\title{
Avaliação do comportamento de misturas asfálticas recicladas a quente com inserção de material fresado
}

\section{Evaluation of the behavior of hot-recycled asphaltic mixtures with reclaimed asphalt}

\author{
Roberta Centofante ${ }^{1}$, Luciano Pivoto Specht ${ }^{2}$, Pedro Orlando Borges de Almeida Junior ${ }^{2}$, \\ Rinaldo José Barbosa Pinheiro², Deividi da Silva Pereira ${ }^{2}$
}

\footnotetext{
${ }^{1}$ Universidade Regional Integrada do Alto Uruguai e das Missões, Departamento de Engenharias e Ciência da Computação, Rua Assis Brasil, 709, Frederico Westphalen, RS, Brasil.

e-mail: robertacentofante@yahoo.com.br

${ }^{2}$ Universidade Federal de Santa Maria, Departamento de Transportes, Av. Roraima, 1000, Santa Maria, RS, Brasil. e-mail: luspecht@ufsm.br; engcivilpedro@hotmail.com; rinaldo@ufsm.br; dsp@ufsm.br
}

\section{RESUMO}

Este trabalho tem por objetivo avaliar a técnica da reciclagem a quente em misturas asfálticas com relação às propriedades mecânicas, a fim de verificar a adequabilidade de seu emprego na substituição de material granular virgem por material reciclado do pavimento (fresado) em diferentes porcentagens, visando sua aplicação em camadas de pavimento. Para atingir este objetivo, foram realizados ensaios laboratoriais a fim de avaliar misturas contendo $10 \%, 20 \%$ e $30 \%$ de adição de fresado, comparadas a uma mistura de referência sem adição do agregado reciclado. Para avaliação de rigidez foram realizados ensaios de módulo de resiliência (MR) e módulo dinâmico uniaxial. Além destes, foram realizados ensaios de resistência à tração indireta (RT) e Flow Number (FN) para avaliação de resistência mecânica e, também, ensaios de dano por umidade induzida, através do Lottman Modificado, e desgaste no ensaio Cântabro, para avaliação das propriedades de adesividade e coesão das misturas, respectivamente. Através da análise dos resultados foi possível verificar uma importante economia do teor de ligante adicionado, visto que o material fresado contém ligante envelhecido e, assim, a redução de ligante novo variou de 12,9\% até 35,7\% para misturas com $10 \%$ e $30 \%$ de material reciclado, respectivamente. $\mathrm{O}$ experimento indicou que a adição de fresado em misturas asfálticas afeta o módulo e aumenta a rigidez das misturas; o ensaio de FN mostrou o ganho de resistência à deformação permanente das misturas, bem como não houve problemas significativos de desgaste e de adesividade, ou seja, as perdas encontradas são insignificantes e não comprometem a utilização deste material.

Palavras-chave: reciclagem a quente; fresado; módulo dinâmico.

\section{ABSTRACT}

The objective of this study is to evaluate the technique of hot recycling in asphalt mixtures relative to the mechanical properties, for the purpose of verify the adequacy of their employment in substitution of virgin granular material for Reclaimed Asphalt Pavement (RAP) in different percentages, for the application in layers of pavement. To achieve the purpose of this study, laboratory tests were made to evaluate the mechanical properties and adhesiveness of mixtures containing 10\% addition of RAP, 20\% and 30\%, compared to a reference mix without RAP. For stiffness evaluation were used resilient modulus tests (RM) and uniaxial dynamic modulus test. Besides these tests was performed the indirect tensile strength tests (RT) and Flow Number test (FN) for mechanical evaluation, damage tests induced moisture through the Modified Lottman test and Cantabro abrasion, for evaluation of the properties of adhesion and cohesion of the mixtures, respectively. Analyzing the results, an important economy of asphaltic binder was observed, whereas the RAP contains aged binder It's possible to reduce the new binder content between $12.9 \%$ and $35.7 \%$ for mixtures with $10 \%$ and $30 \%$ recycled material, respectively. The experiment indicated the RAP addition affects the modulus and increases the stiffness of the mixtures; the FN test showed the resistance 
gain to the permanent deformation of the mixtures as well as there were no significant problems of adhesion, in other words, the losses are insignificant and do not compromise the use of this material.

Keywords: hot recycling; RAP; dynamic modulus.

\section{INTRODUÇÃO}

O pavimento asfáltico representa uma estrutura de múltiplas camadas de espessuras finitas formado, de maneira geral, por revestimento asfáltico, base, sub-base e reforço do subleito, onde o revestimento tem como principal função resistir, de forma direta, aos esforços oriundos do tráfego, além de impermeabilizar o pavimento e melhorar as condições de rolamento [1- 3].

Os mecanismos de degradação de um pavimento flexível, notadamente o trincamento por fadiga e as deformações permanentes excessivas, são resultantes da ação climática e do tráfego, e dependem principalmente das tensões e deformações atuantes na estrutura [1- 2]. Tanto a rigidez quanto as espessuras das camadas determinam a maneira como serão distribuídos os esforços; camadas estruturais mais rígidas e maiores espessuras elevam o grau de abertura do cone de tensões e reduzem os esforços solicitantes nas camadas subjacentes. A rigidez das misturas asfálticas pode ser simplificada considerando o material como um sólido elástico, todavia herdam a característica da viscoelasticidade do ligante nelas contido e, também, tornam-se susceptíveis a variações de temperatura e de frequência de aplicação de carga. O comportamento viscoelástico linear de ligantes e misturas tem sido estudado por diversos autores [10-16], através de modelos desenvolvidos para capturar os efeitos de carregamento, envelhecimento, umidade e temperatura sobre o comportamento do concreto asfáltico.

Em comparação a outras estruturas de engenharia, o pavimento asfáltico é uma estrutura que apresenta uma vida útil menor e, por isso, deve-se utilizar técnicas de manutenção mais elaboradas como, por exemplos, a fresagem e a reciclagem de pavimentos. Atualmente, em muitos países, são empregadas técnicas de reciclagem como forma de agregar valor à execução e à manutenção da vida útil dos pavimentos, visto que estas representam técnicas sustentáveis e alternativas economicamente viáveis. Portanto, visando a redução de custos e manutenção e, ainda, o aumento de sua vida útil aliado à questão ambiental, inúmeras tecnologias de reciclagem de pavimento estão sendo testadas e aplicadas por diversos autores [4- 9].

A reutilização de materiais reciclados em camadas de pavimento, como o fresado em camadas novas, consiste na aplicação desse resíduo a fim de obter uma redução no valor econômico, no consumo de materiais novos, aumentado a capacidade de carga, e proteger o meio ambiente. O impacto dos materiais de pavimentação de asfaltos recuperados (Reclaimed Asphalt Pavement - RAP) no desempenho de um pavimento representa um importante tema de estudo na indústria, devido, principalmente, aos benefícios ambientais e econômicos. A principal preocupação com o aumento das porcentagens admissíveis de RAP em mistura a quente é a presença de materiais envelhecidos, os quais podem fragilizar a mistura e diminuir a sua resistência, sobretudo à fadiga [12, 17-18].

A utilização de RAP aumenta na medida em que as agências de transporte fazem uso mais eficiente de seus recursos. A viabilidade da utilização do RAP em misturas asfálticas é devido à presença do Cimento Asfáltico de Petróleo (CAP) oxidado, o qual apresenta maior rigidez que o CAP novo, além da atividade relativa ao uso de uma matéria-prima com custo inferior a partir da reciclagem, considerando elevados percentuais de uso da mesma [12, 19].

No entanto, apesar de o uso de RAP em misturas a quente ter se tornado uma prática comum nas últimas décadas, em países europeus e nos Estados Unidos, com quase todas as misturas contendo alguma porcentagem do material reciclado, porém, muitas agências de transportes norte-americanas têm relutado em permitir que se use mais de $10 \%$ a $20 \%$ de RAP. Uma das principais razões para essa relutância é devido às preocupações de que as misturas resultantes serão muito rígidas e, consequentemente, menos trabalháveis, difíceis de compactar e, ainda, que podem levar a misturas propensas a falhas em campo, como, por exemplo, a adesividade em relação ao efeito deletério da água e à fadiga do pavimento asfáltico recuperado [5-7, 20 22].

Neste contexto, este trabalho tem por objetivo a avaliação laboratorial da técnica da reciclagem a quente em misturas asfálticas no que tange às propriedades mecânicas e de adesão/coesão, a fimm de verificar a pertinência de seu emprego na substituição de material granular virgem por RAP em diferentes porcentagens, visando sua aplicação em camadas de pavimento.

\section{MATERIAIS E MÉTODOS}

A pesquisa consiste na preparação e teste de uma mistura de referência e de misturas com adição de material fresado nas proporções de $10 \%, 20 \%$ e $30 \%$ para avaliação de dosagem e propriedades mecânicas de rigidez e resistência e, também, para avaliação das propriedades de adesão e coesão. 
Os materiais desta pesquisa são aqueles convencionalmente utilizados em projetos de rodovias em concreto asfáltico, além da adição de material fresado, proveniente de processo de fresagem da Rodovia BR392, em trecho próximo ao km 338 entre os municípios de Santa Maria/RS e São Sepé/RS.

Foram realizados ensaios para caracterização do material fresado para determinação do teor de ligante, o qual apresentou teor de ligante médio de $6,76 \%$, de acordo com o ensaio de centrífuga Rotarex (DNER-ME 053/1994) [23], e massa específica de $2,367 \mathrm{~g} / \mathrm{cm}^{3}$, obtida através da metodologia Rice (ABNT NBR 15619/2012) [24].

Os agregados virgens utilizados nas misturas foram obtidos através de processo de britagem e coletados diretamente das unidades de produção, os quais foram fornecidos por uma empresa da região de Santa Maria/RS. Foram utilizadas frações de agregados 3/4", 3/8" e pó-de-pedra de origem de rochas vulcânicas ácidas, com valores de abrasão Los Angeles de 14,35\% seguindo a norma DNER-ME 035/98 [25], sanidade da brita 3/4" de 2,86\% e da brita 3/8" de 0,19\% através da DNER-ME 089/94 [26] e equivalente de areia de 80,04\%, de acordo com a norma DNER-ME 054/97 [27].

O ligante asfáltico utilizado foi o CAP 50/70, fornecido também por uma empresa da Região de Santa Maria/RS. Quanto à caracterização do ligante, a viscosidade [28], propriedades reológicas através do Dynamic Shear Rheometer (DSR) [29], perda de massa [30], especificação de Performance Grade utilizando o Multiple Stress Creep Recovery (MSCR) [31] e rigidez com Bendin Beam Rheometer (BBR) [32], estão apresentados na Tabela 1.

Tabela 1: Resultados dos ensaios de caracterização do ligante 50/70

\begin{tabular}{|c|c|c|c|}
\hline \multirow{2}{*}{ Ligante } & Ensaio & Resultados & Limites \\
\hline & $\mathrm{CPG}$ & $58 \mathrm{H}-28$ & - \\
\hline \multirow{4}{*}{ Ligante Original } & \multirow{3}{*}{ Viscosidade [28] } & $333\left(135^{\circ} \mathrm{C}\right)$ & \\
\hline & & $138\left(150^{\circ} \mathrm{C}\right)$ & - \\
\hline & & $68\left(177^{\circ} \mathrm{C}\right)$ & \\
\hline & DSR - $\left|G^{*}\right| / \operatorname{sen}(\varphi)$ [29] & $\begin{array}{l}2,96\left(58^{\circ} \mathrm{C}\right) \\
1,32\left(64^{\circ} \mathrm{C}\right) \\
0,62\left(70^{\circ} \mathrm{C}\right)\end{array}$ & $\geq 1,00 \mathrm{kPa}$ \\
\hline \multirow{4}{*}{$\begin{array}{c}\text { Ligante Envelhecido } \\
\text { no RTFOT }\left(\mathrm{T}=163^{\circ} \mathrm{C}\right)\end{array}$} & Perda de Massa [30] & $-0,04$ & $< \pm 1,00 \%$ \\
\hline & DSR - $\left|G^{*}\right| / \operatorname{sen}(\varphi)[29]$ & $\begin{array}{l}4,93\left(58^{\circ} \mathrm{C}\right) \\
2,09\left(64^{\circ} \mathrm{C}\right) \\
0,93\left(70^{\circ} \mathrm{C}\right)\end{array}$ & $\geq 2,20 \mathrm{kPa}$ \\
\hline & \multirow[t]{2}{*}{ MSCR [31] } & $1,91\left(58^{\circ} \mathrm{C}\right)$ & $\begin{array}{l}\mathrm{S}[2,0<\mathrm{jnr} \leq 4,5] \\
\mathrm{H}[1,0<\mathrm{jnr} \leq 2,0] \\
\mathrm{V}[0,5<\mathrm{jnr} \leq 1,0] \\
\mathrm{E}[0,0<\mathrm{jnr} \leq 0,5]\end{array}$ \\
\hline & & $5,50 \%$ & $\leq 75 \%$ \\
\hline \multirow{3}{*}{$\begin{array}{c}\text { Ligante Envelhecido } \\
\text { no RTFOT + PAV } \\
\left(\mathrm{T}=163^{\circ} \mathrm{C}\right)\end{array}$} & DSR $\left|G^{*}\right| \operatorname{sen}(\varphi)$ [29] & $\begin{array}{l}11198\left(19^{\circ} \mathrm{C}\right) \\
7442\left(22^{\circ} \mathrm{C}\right) \\
4998\left(25^{\circ} \mathrm{C}\right)\end{array}$ & $\leq 6000 \mathrm{kPa}$ \\
\hline & BBR Módulo de rigidez -S [32] & $\begin{array}{c}52\left(-6^{\circ} \mathrm{C}\right) \\
135\left(-12^{\circ} \mathrm{C}\right) \\
278\left(-18^{\circ} \mathrm{C}\right)\end{array}$ & $\leq 300 \mathrm{MPa}$ \\
\hline & Coeficiente angular $-\mathrm{m}$ [32] & $\begin{array}{c}0,428\left(-6^{\circ} \mathrm{C}\right) \\
0,330\left(-12^{\circ} \mathrm{C}\right) \\
0,316\left(-18^{\circ} \mathrm{C}\right)\end{array}$ & $\geq 0,300$ \\
\hline
\end{tabular}

No ajuste granulométrico buscou-se uma mistura que estivesse enquadrada nos limites prescritos para a Faixa C da norma DNIT 031/2006-ES [33], sendo que, depois de tomada uma mistura de referência contendo apenas materiais virgens, a composição granulométrica dos agregados foi realizada utilizando-se o método tradicional de tentativas. A partir da mistura de referência (CAref), foram aplicadas as sugestões do método Bailey para proporcionamento dos componentes, detalhado por Mendes e Marques [34] obtendo-se, assim, uma mistura que se enquadrasse nos parâmetros do método, bem como nos limites exigidos pela especificação da Faixa C do DNIT (Departamento Nacional de Infraestrutura de Transportes). O mesmo foi realizado para as misturas contendo material fresado (CAF10, CAF20 e CAF30), sendo que, primeiramente, 
foi estipulada e fixada a porcentagem deste material reciclado e, após, seguindo o método de tentativas, foi realizado o enquadramento das misturas respeitando os dois parâmetros citados, resultando em misturas de curvas granulométricas apresentadas na Figura 1.

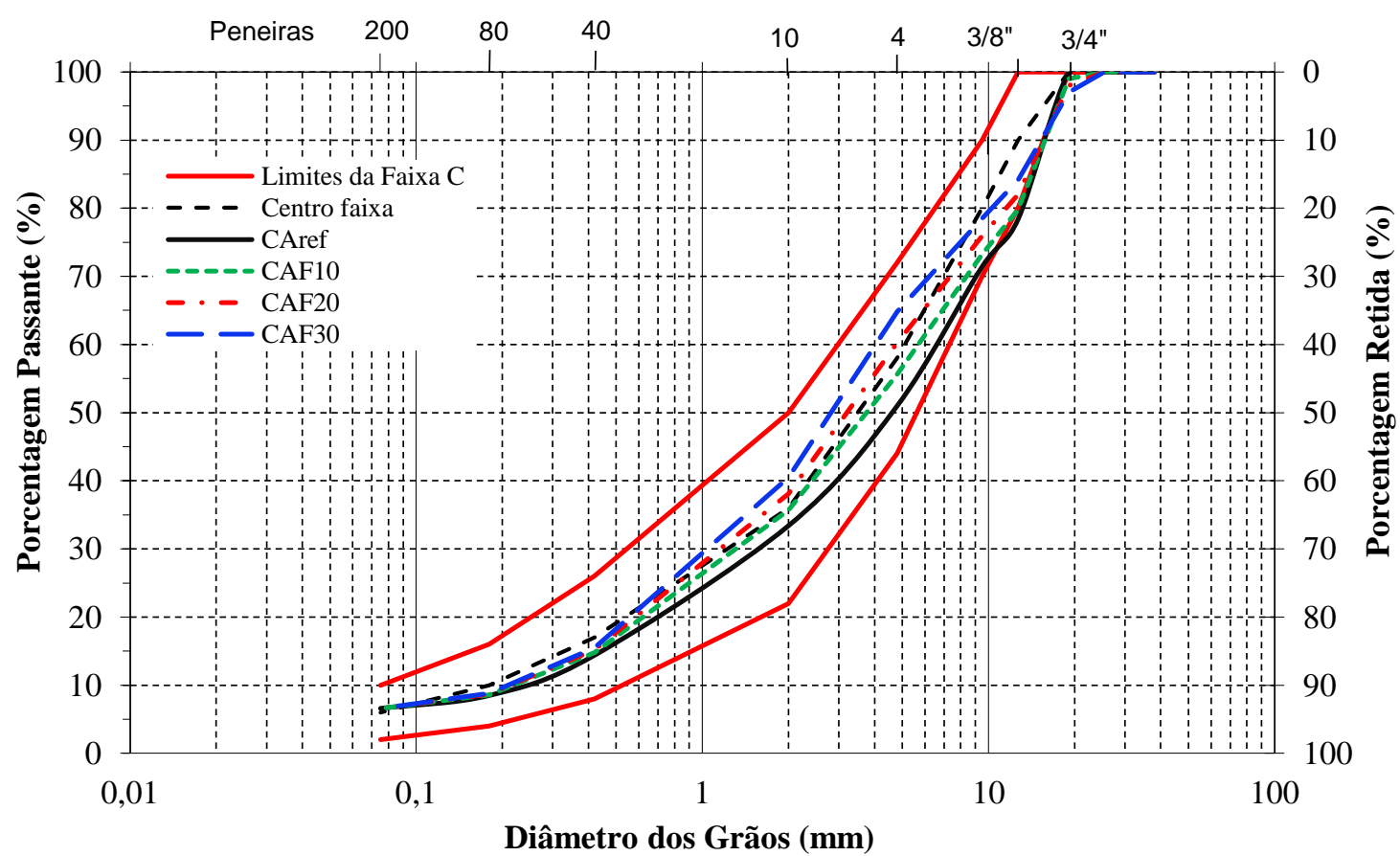

Figura 1: Composição granulométrica das misturas utilizadas na pesquisa

Foram utilizadas, para a determinação dos teores de ligante de projeto, no procedimento de dosagem, três amostras para cada teor de ligante. O projeto de mistura foi executado de acordo com os procedimentos determinados para dosagem Superpave, seguindo os preceitos da norma da AASHTO M 323-13 [35] considerando o agregado reciclado como black rock, aplicando os critérios de projeto nível 1 (critério volumétrico), o qual depende do tráfego, com valores limite de tráfego (número $\mathrm{N}$ ), e da importância da rodovia [3]. Através da curva volume vazios x ligante, foi possível determinar, para cada uma das misturas, o teor de ligante correspondente ao Volume de vazios (Vv) de 4\%, com esforço de compactação de projeto baseado no número de giros de projeto (Nprojeto), o qual corresponde a um valor, utilizado nesta pesquisa, igual a 100, que representa um tráfego equivalente à carga de eixo simples entre $3 \times 10^{6}$ e $3 \times 10^{7}$ (AASHTO), considerado em vias de tráfego médio a pesado.

Com relação ao processo de moldagem e materiais utilizados, maiores informações podem ser obtidas em AUTOR (2016).

\subsection{Propriedades analisadas}

\subsubsection{Rigidez}

Através do ensaio de Módulo de Resiliência (MR) foi possível avaliar a propriedade de rigidez considerando o material puramente elástico, da forma como se utiliza na prática corrente brasileira. $\mathrm{O}$ ensaio foi realizado de acordo com as prescrições da norma do DNIT-ME 135/2010 [36]. O ensaio tem como intuito determinar a capacidade que um corpo elástico tem de armazenar energia quando solicitado a um carregamento e, após, retornar ao seu estado inicial. Consiste, basicamente, em aplicar uma carga repetidamente no plano diametral vertical em 5 amostras, de cada mistura, cilíndricas regulares com $10 \mathrm{~cm}$ de diâmetro e $6,5 \mathrm{~cm}$ de altura e $\mathrm{Vv}$ de 4\%. Tal carga gera uma tensão na qual mede-se o deslocamento diametral recuperável na direção horizontal correspondente à tensão aplicada, na temperatura de $25^{\circ} \mathrm{C}$. Cada amostra foi ensaiada em três frequências de carregamento: $5 \mathrm{~Hz}, 10 \mathrm{~Hz}$ e $25 \mathrm{~Hz}$, sendo que o coeficiente de Poisson utilizado foi de 0,30, e à temperatura de $25^{\circ} \mathrm{C}$, conforme recomendação normativa [36].

$\mathrm{O}$ ensaio de módulo dinâmico, para avaliação da rigidez sob a ótica da viscoelasticidade linear, foi realizado com 3 amostras de cada mistura com $10 \mathrm{~cm}$ de diâmetro e $15 \mathrm{~cm}$ de altura, apresentando volume de 
vazios de 5,5\% $( \pm 0,5 \%)$. O módulo complexo foi determinado após aplicação de carga em diferentes frequências $(25 \mathrm{~Hz}, 20 \mathrm{~Hz}, 10 \mathrm{~Hz}, 5 \mathrm{~Hz}, 2 \mathrm{~Hz}, 1 \mathrm{~Hz}, 0,5 \mathrm{~Hz}, 0,2 \mathrm{~Hz}, 0,1 \mathrm{~Hz}$ e $0,01 \mathrm{~Hz}$ ) e temperaturas ($10^{\circ} \mathrm{C}, 4^{\circ} \mathrm{C}, 21^{\circ} \mathrm{C}, 37^{\circ} \mathrm{C}$ e $54^{\circ} \mathrm{C}$ ). $\mathrm{O}$ condicionamento das amostras, bem como toda a realização do ensaio, seguiram os preceitos da norma AASHTO T 342 [37]. Ambos os ensaios foram realizados utilizando uma Universal Test Machine (UTM), da fabricante IPC Global, do Laboratório de Materiais de Construção Civil da Universidade Federal de Santa Maria (UFSM).

A deformação axial controlada foi fixada entre 50 e 75 microstrains, no intuito de buscar um regime de viscoelasticidade linear. O cálculo de ajuste para alcançar esta faixa de deformação é realizado através da Equação 1. A relação tensão-deformação durante o carregamento senoidal contínuo, para materiais viscoelásticos lineares, é definida por um número complexo chamado de Módulo Complexo (E*). O módulo complexo é formado por duas parcelas, o módulo dinâmico e o ângulo de fase. O valor absoluto de módulo complexo, $\left|E^{*}\right|$, é definido como Módulo Dinâmico. O módulo dinâmico é matematicamente definido como a tensão dinâmica $\left(\sigma_{0}\right)$ dividida pela deformação axial recuperável máxima $\left(\varepsilon_{0}\right)$.

$$
\left|E^{*}\right|=\underline{\sigma}_{0}
$$

As porções real e imaginária do módulo complexo podem ser escritas de acordo com a Equação 2.

$E^{*}=E 1+E 2$

Onde E1 representa, genericamente, a fração de armazenamento ou a fração elástica do módulo complexo, e o E2 representa a fração de perda ou a fração viscosa do módulo.

Além disso, o ângulo de fase, $\varphi$, que é definido como um indicador das propriedades viscosas do material ensaiado, pode ser representado como o ângulo de atraso de $\varepsilon_{0}$ em relação a $\sigma_{0}$, conforme a Equação 3:

$$
\varphi=\frac{t i}{t p} \times 360
$$

Onde $t i$ representa a fração de tempo entre os picos de tensão e deformação, $t p$ corresponde tempo de um ciclo de carga e $i$ é um número imaginário.

Portanto, para um material puramente elástico $\varphi=0^{\circ}$, o módulo complexo será igual ao módulo dinâmico. Para um material puramente viscoso, por outro lado, o valor de $\varphi$ será igual a $90^{\circ}$ [11].

O valor do módulo complexo varia em função dos parâmetros de ensaio, temperatura e velocidade de carregamento, e os parâmetros da formulação do material betuminoso, natureza e teor do ligante, percentual granular e de finos e a forma de compactação. A execução do ensaio em diferentes frequências de carregamento e temperatura permitiu, a partir da utilização da propriedade de equivalência tempotemperatura, obter uma curva contínua (frequência-temperatura) chamada de curva mestra. Esta representa a união das curvas através de pontos com mesmo valor de módulo do material, para uma temperatura de referência (Tr), escolhida arbitrariamente, com a translação paralela dos eixos das frequências de cada isotérmica relacionada com a isotérmica correspondente e a temperatura de referência, até a superposição de pontos de mesma ordenada. Logo, a curva mestra se torna um importante instrumento de caracterização da rigidez da mistura para dimensionamento de pavimentos [38-40].

A construção de curvas mestras pode ser realizada usando uma temperatura de referência arbitrariamente selecionada para todos os dados reológicos analisados. Na temperatura de referência o shift tem valor igual a um, ou seja, $\log$ a(T) é igual a zero. Para o caso desta pesquisa, a temperatura foi fixada em $20^{\circ} \mathrm{C}$. Logo, uma das grandes vantagens da curva mestra é a possibilidade da previsão dos valores de uma determinada propriedade reológica ao longo de uma gama de frequências mais ampla do que a efetivamente medida, bem como nas mais variadas temperaturas.

Os resultados de módulo complexo foram também modelados através do modelo 2S2P1D (2 Springs, 2 Parabolic, 1 Dashpot) [11], apresentado na Figura 2, através do plano Cole Cole, que representa a curva característica de determinado material em estudo. Tal modelo foi desenvolvido para modelagem completa, através de 7 ou 9 parâmetros, das propriedades viscoelásticas lineares de materiais asfálticos para os casos bi ou tridimensionais. 

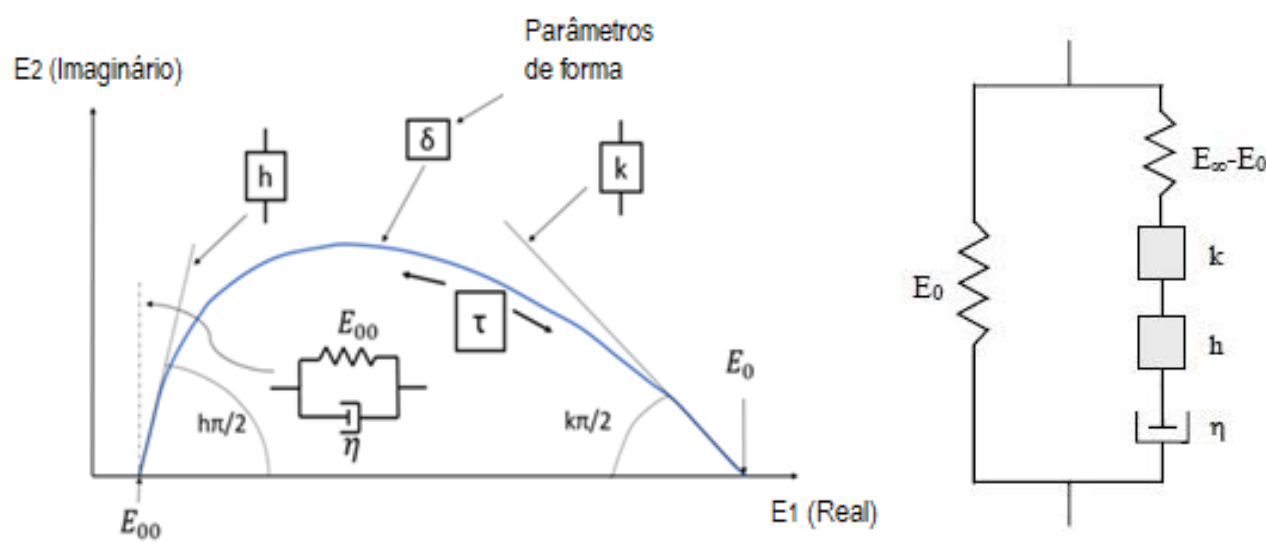

Figura 2: Representação no plano Cole Cole do modelo 2S2P1D (a) e sua representação física (b) [11]

\subsubsection{Resistência Mecânica}

O ensaio para avaliar a resistência à tração por compressão diametral (RTCD ou RT) foi realizado utilizandose as mesmas 5 amostras para cada mistura do ensaio de MR. As amostras foram condicionadas por um período de 12 horas antes da realização do ensaio, sendo realizado à temperatura de $25^{\circ} \mathrm{C}$. A norma que prescreve as orientações utilizadas para a determinação da RT foi DNIT 136/2010 [41]. O ensaio consiste em aplicação de uma carga estática de compressão com velocidade de $0,8 \mathrm{~mm} / \mathrm{s}$, distribuída ao longo de duas geratrizes opostas, a fim de se obter as tensões de tração através do diâmetro horizontal, perpendicular à carga, onde a medida resultante é a resistência à tração, que representa uma inferência à fadiga.

Para avaliação da resistência à deformação permanente foi realizado o ensaio de Flow Number (FN) de acordo com as normas AASHTO TP 79-12 [42] e a ABNT NBR 16505/2016 [43]. Consiste basicamente em um teste de desempenho simples de misturas de concreto asfáltico para deformação permanente com base em cargas repetidas. Neste teste, a amostra é primeiramente condicionada para a temperatura específica, e submetida a um carregamento repetido axial com pulso de carga de compressão. O FN é definido como o número de ciclos de carga correspondente à taxa mínima de mudança de tensão permanente.

Para a realização deste ensaio foram utilizadas 2 amostras de cada mistura contendo volume de vazios de 7\% ( $\pm 0,5 \%)$ e Grau de Compactação (GC) de 97\% ( $\pm 0,5 \%)$, com $10 \mathrm{~cm}$ de diâmetro e $15 \mathrm{~cm}$ de altura. As amostras foram condicionadas a $60^{\circ} \mathrm{C}$ por um período de 5 horas. As deformações acumuladas foram obtidas em função do número de ciclos, e a tensão aplicada em cada ciclo do ensaio foi de $204 \mathrm{kPa}$ no período de 0,1 $\mathrm{s}$ e de $10,2 \mathrm{kPa}$ durante os $0,9 \mathrm{~s}$ de repouso, que representa o descanso com uma carga equivalente a $5 \%$ da carga aplicada. A curva de deformação plástica vertical uniaxial de cada corpo de prova foi ajustada ao modelo de Francken, que é uma combinação dos modelos de potência e exponencial [43]. O FN corresponde a mudança de comportamento do material (de secundário, taxa de deformação praticamente constante para terciário, taxa de deformação crescente) indicando a incapacidade do material a resistir ao carregamento imposto.

\subsubsection{Adesão/Coesão}

A avaliação da durabilidade do material ou da perda de adesão/coesão ocorreu através de duas técnicas laboratoriais (dano por umidade induzida e perda de massa). A metodologia utilizada para o caso do dano por umidade induzida foi o Ensaio Lottman Modificado normalizado pela AASHTO T 283 [44] e ABNT NBR 15617/2011 [45], em que 6 amostras compactadas cilíndricas de cada mistura com volume de vazios preestabelecidos $(7 \% \pm 1 \%)$ são divididas em dois grupos de 3 amostras; em um grupo as são parcialmente saturadas com água e submetidas à temperatura de $-18^{\circ} \mathrm{C}$ para congelamento, simulando, com isso, a presença de água na mistura e induzindo tensões internas. As amostras descongeladas, aquecida a $60^{\circ} \mathrm{C}$ e depois à temperatura de equilíbrio de $25^{\circ} \mathrm{C}$ quando são submetidas ao ensaio de resistência à tração (e denominadas RT'). O outro conjunto similar de amostras, não submetidas ao processo de saturação e congelamento, são igualmente submetidas ao ensaio de RT à temperatura de $25^{\circ} \mathrm{C}$. A relação entre RT'/RT indica a perda de resistência por umidade induzida ou resistência retida à tração (RRT). Essa relação deve ser maior ou igual a 0,70 , ou seja, a perda deve ser inferior a $30 \%$.

Para análise da perda de massa foi realizado o ensaio de Desgaste Cântabro. Este ensaio consistiu na análise de 8 amostras de cada mistura submetidas ao aparelho e abrasão Los Angeles, sem esferas metálicas, à 300 revoluções, onde, apesar de sua concepção estar relacionada para pavimentos drenantes, o ensaio pode 
ser estendido para outros tipos de misturas asfálticas, normatizados através da ABNT NBR 15140/2004 [46]. O desgaste máximo admitido é de $25 \%$ para misturas asfálticas porosas. Para o ensaio de perda de massa cântabro foram moldadas amostras com volume de vazios de $4 \%( \pm 1 \%)$ e ensaiadas após condicionamento de 12 horas a $25^{\circ} \mathrm{C}$.

\section{RESULTADOS}

\subsection{Parâmetros volumétricos}

Com os valores provenientes do procedimento de dosagem, foi possível determinar cada um dos teores de projeto, os quais estão apresentados na Tabela 2, bem como os resultados dos parâmetros volumétricos de cada mistura, com Vv de 4\%. É possível verificar uma importante economia no teor de ligante adicionado, visto que, quanto maior a porcentagem de fresado existente na mistura, e, consequentemente, maior a taxa de ligante antigo, menor a porcentagem de ligante novo necessário. Esta redução variou de 12,9\% a 35,7\% para mistura com $10 \%$ e $30 \%$, respectivamente.

Tabela 2: Resultados volumétricos das dosagens Superpave das misturas asfálticas

\begin{tabular}{lccccccc}
\hline \multirow{2}{*}{ Mistura } & $\begin{array}{c}\text { Volume de } \\
\text { vazios }(\%)\end{array}$ & $\begin{array}{c}\text { Teor de Ligante } \\
\text { Adicionado }(\%)\end{array}$ & $\begin{array}{c}\text { Teor de Ligante } \\
\text { Antigo }(\%)\end{array}$ & $\begin{array}{c}\text { Teor de Ligante } \\
\text { Total }(\%)\end{array}$ & $\begin{array}{c}\text { Proporção Ligante } \\
\text { Adicionado e Antigo (\%) }\end{array}$ & $\begin{array}{c}\text { VAM } \\
(\%)\end{array}$ & $\begin{array}{c}\text { RBV } \\
(\%)\end{array}$ \\
\hline CAref & 4,00 & 5,70 & - & 5,70 & $100,0 / 0,0$ & 17,3 & 76,8 \\
CAF10 & 4,00 & 4,60 & 0,68 & 5,28 & $87,1 / 12,9$ & 15,0 & 74,0 \\
CAF20 & 4,00 & 4,15 & 1,35 & 5,50 & $75,4 / 24,6$ & 16,0 & 65,0 \\
CAF30 & 4,00 & 3,65 & 2,03 & 5,68 & $64,3 / 35,7$ & 14,5 & 75,0 \\
\hline
\end{tabular}

Nota: VAM = Volume de vazios do agregado mineral; RBV = Relação Betume Vazios

\subsection{Rigidez}

A Tabela 3 e na Figura 3 são apresentados os valores de MR para cada uma das misturas, em todas as frequências ensaiadas e temperatura de $25^{\circ} \mathrm{C}$, sendo que os resultados apresentados são formados pela média de três amostras ensaiadas nas mesmas condições, com seus respectivos desvios-padrões (DP). Foi possível verificar que os maiores valores de rigidez são aqueles onde a frequência aplicada foi a mais alta $(25 \mathrm{~Hz})$, confirmando a natureza viscoelástica do material analisado.

Tabela 3: Resultados de MR à temperatura de $25^{\circ} \mathrm{C}$

\begin{tabular}{ccccccc}
\hline Mistura & $M R(M P a) 5 \mathrm{~Hz}$ & $D P(M P a)$ & $M R(M P a) 10 \mathrm{~Hz}$ & $D P(M P a)$ & $M R(M P a) 25 \mathrm{~Hz}$ & $D P(M P a)$ \\
\hline CAref & 3754 & 175 & 5138 & 194 & 6358 & 155 \\
CAF10 & 5715 & 179 & 6575 & 166 & 8665 & 56 \\
CAF20 & 6108 & 296 & 6755 & 222 & 7895 & 319 \\
CAF30 & 6405 & 126 & 7506 & 313 & 8525 & 252 \\
\hline
\end{tabular}




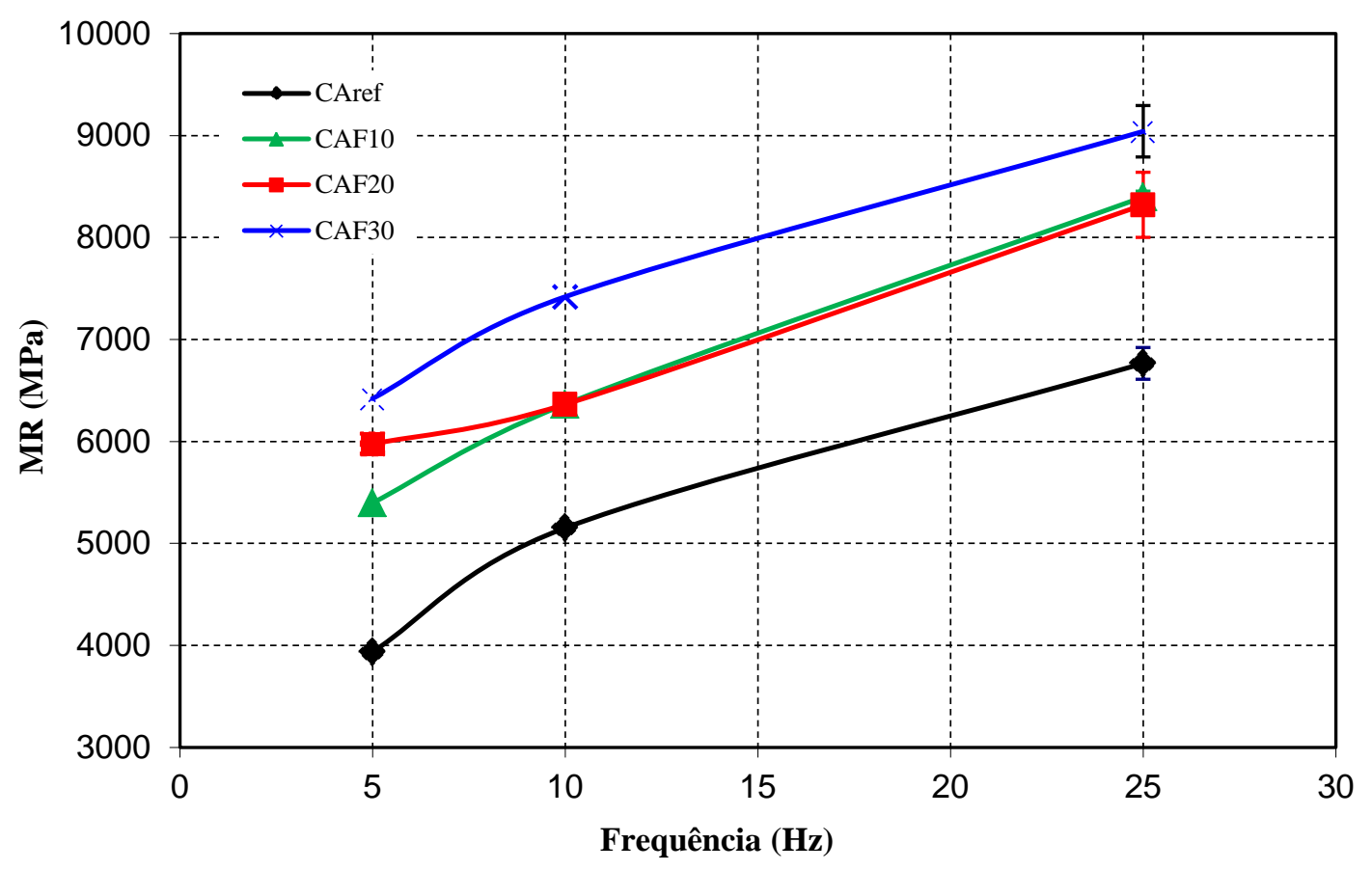

Figura 3: Resultados de $\mathrm{MR}$ a $25^{\circ} \mathrm{C}$ em função da frequência de carregamento

Através dos dados é possível verificar que as misturas apresentaram, no geral, um aumento de rigidez com o aumento da quantidade de fresado, devido, possivelmente a presença de ligante já envelhecido (visto que a quantidade de ligante total nas misturas é muito próxima). Quando se analisa o comportamento das misturas em relação às diferentes frequências, nota-se que, independentemente do valor, a mistura CAref sempre apresenta menor rigidez que as demais.

Considerando os valores medidos a $10 \mathrm{~Hz}$ [36], verificam-se valores bastante típicos de concretos asfálticos convencionais. Sob a ótica da Mecânica de Pavimentos o incremento de rigidez causado pela incorporação do RAP pode ser aproveitado no projeto estrutural como uma camada portante importante que complemente ou substitua o revestimento ou ainda como base negra ou como mistura asfáltica de alto módulo; neste caso é relevante a avaliação quanto à fadiga. Em trabalho laboratorial, com relação ao aumento da rigidez proporcionado pelo fresado, Segundo et al. [19] também encontraram a mesma lógica de tendência de aumento de rigidez com a inserção do fresado.

É importante ressaltar ainda que, devido à grande heterogeneidade do material fresado, as misturas CAF10 e CAF20 não seguiram exatamente o padrão, sendo que a CAF20 deveria apresentar maior rigidez quando comparada com a CAF10, o que pode ser observado através da Figura 3, onde a CAF10 apresenta, levemente, maior rigidez.

Com relação ao comportamento viscoelástico, a representação gráfica dos resultados de módulo dinâmico pode ser observada no espaço Cole Cole apresentado na Figura 4, para todas as misturas, com a média das amostras, para os resultados experimentais e, também, aqueles obtidos através da modelagem 2S2P1D. Na Cole Cole é representada, em escala aritmética, a parte real E1 e a parte imaginária ou de perda E2. A partir da análise da Figura 3, fica claro que os dados formam curvas de formato semicircular, o qual era esperado para a Cole Cole e, ainda, que a mistura de referência apresenta os menores valores de E2, no geral, quando comparadas às misturas com adição de fresado. Além disso, com relação ao eixo viscoso E2, os valores são, praticamente os mesmos, estando a diferença maior, no geral, no eixo E1, onde à medida em que se adiciona fresado aumenta a rigidez, corroborando com a análise elástica analisada no MR.

Além disso, é possível verificar na Cole Cole a inversão de valores entre as misturas CAF10 e CAF20, onde existia a tendência de que a mistura CAF10 fosse menos rígida que a mistura CAF20, o que não ocorre nos resultados. Por isso, quando se obteve esses valores, todos os ensaios foram refeitos para essas misturas, inclusive a moldagem das amostras, sendo, no entanto, confirmados os resultados. Contudo, encontra-se na literatura, pesquisas semelhantes, onde os valores também sofreram inversão [16], corroborando o fato e de que não existe uma definição patente acerca deste fato. 


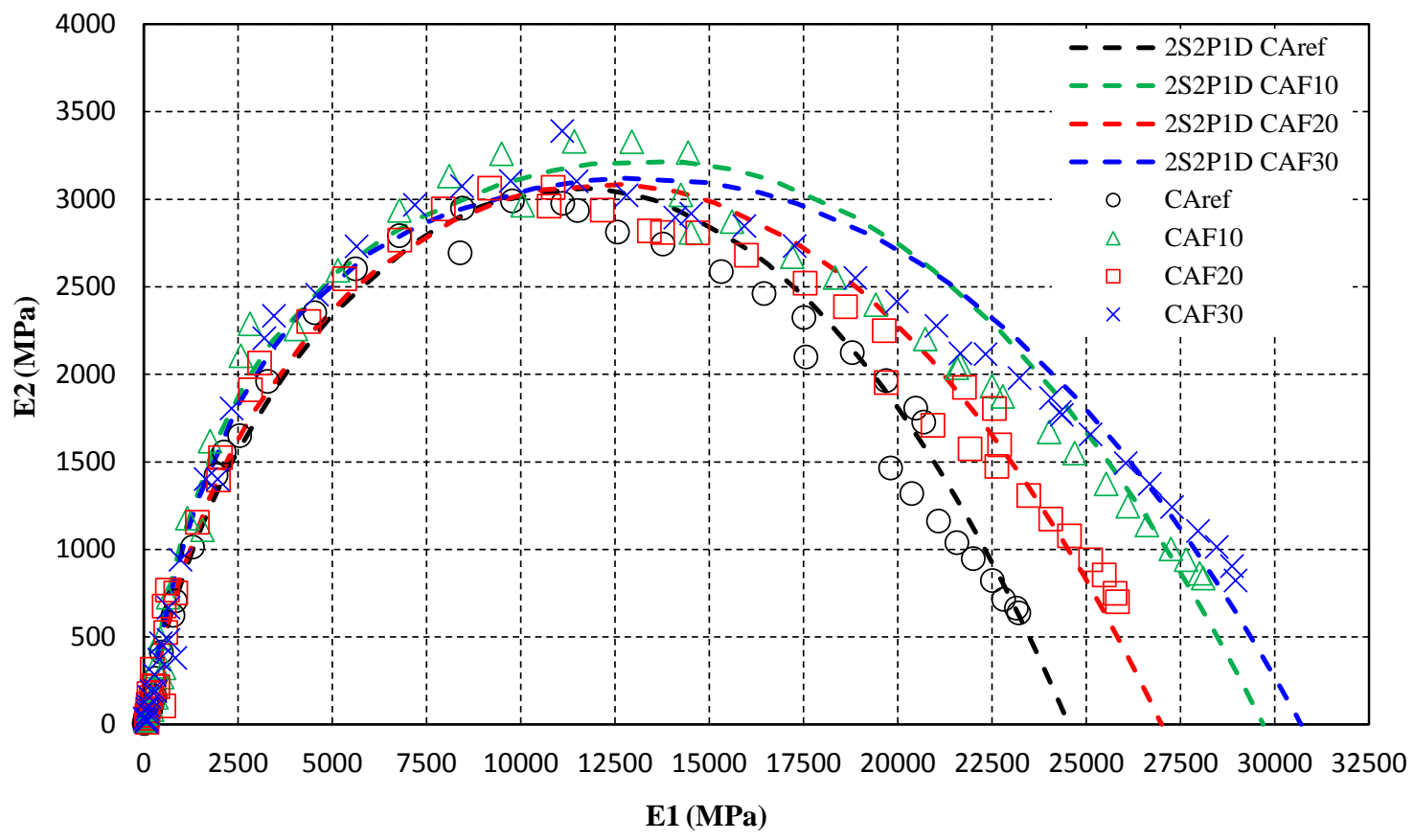

Figura 4: Espaço Cole Cole para todas as misturas com a média das amostras

A representação gráfica dos resultados no Diagrama Black para todas as misturas, tanto para os resultados experimentais, quanto para os obtidos através da modelagem 2S2P1D está apresentada na Figura 5. É possível verificar a relação entre o módulo dinâmico e o ângulo de fase para diferentes temperaturas. Nota-se que a região dos módulos onde ocorre o acréscimo do ângulo de fase é identificada para condições de temperatura elevada (a partir de $37^{\circ} \mathrm{C}$ até $54^{\circ} \mathrm{C}$ ) e, ainda, observa-se que a mistura CAF10, na modelagem, apresenta os maiores valores de ângulo de fase, onde, através dos dados experimentais, foi verificado que isso ocorre com a mistura CAF20, ou seja, essas misturas apresentam uma parcela viscosa mais importante, com relação à parcela elástica. Ainda através do espaço Black, foi possível verificar que, para a temperatura mais elevada de $54^{\circ} \mathrm{C}$, os resultados ficaram fora do padrão com relação às outras temperaturas, possivelmente devido aos ângulos de fase indicarem a fluência do material asfáltico na interface dos instrumentos de medida.

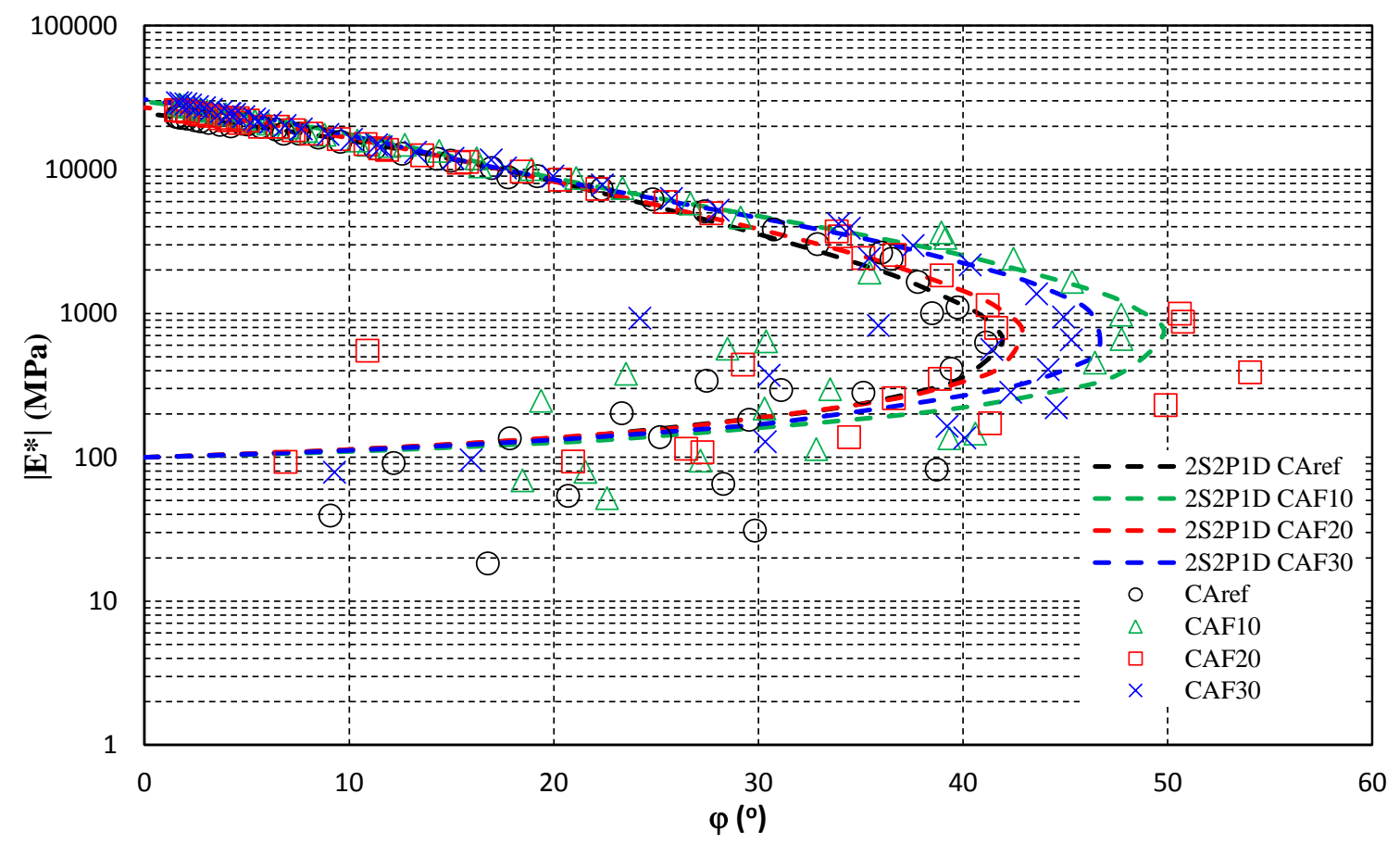

Figura 5: Diagrama Black para todas as misturas 
Tendo em vista o comportamento termoreológico simples das misturas, a partir dos resultados de módulo dinâmico e ângulo de fase, foram construídas curvas mestras, através do princípio da superposição tempo-temperatura (TTSP - time-temperature superposition principle).

Utilizando o modelo reológico 2S2P1D para a construção da curva mestra das misturas, os resultados experimentais e os parâmetros do modelo foram ajustados com as constantes C1 e C2 do modelo WLF [47], de acordo com a Tabela 4. A partir deste modelo constitutivo se torna possível a programação automática de um sistema de análise estrutural e, assim, em função de velocidades e temperaturas determina-se a rigidez do material e, consequentemente, suas respostas mecânicas.

Tabela 4: Parâmetros do modelo 2S2P1D e valores de C1 e C2 para todas as misturas

\begin{tabular}{c|ccccccc|cc}
\hline \multirow{2}{*}{ Mistura } & \multicolumn{7}{|c|}{ Parâmetros de calibração do modelo 2S2P1D } & \multicolumn{2}{c}{$W L F$} \\
\cline { 2 - 11 } & $E_{00}(\mathrm{MPa})$ & $E_{0}(\mathrm{MPa})$ & $\delta$ & $k$ & $\beta$ & $h$ & $\tau_{E}(s)$ & $C 1$ & $C 2\left({ }^{\circ} \mathrm{C}\right)$ \\
\hline CAref & 100 & 24540 & 3,90 & 0,297 & 900 & 0,695 & 0,4 & 52,48 & 377,24 \\
\hline CAF10 & 100 & 29700 & 3,50 & 0,260 & 900 & 0,760 & 0,5 & 63,51 & 437,38 \\
\hline CAF20 & 100 & 27000 & 3,45 & 0,270 & 900 & 0,680 & 0,4 & 57,52 & 420,35 \\
\hline CAF30 & 100 & 30700 & 3,20 & 0,240 & 900 & 0,705 & 0,6 & 53,03 & 388,21 \\
\hline
\end{tabular}

Nota: $\mathrm{E}_{00}=$ módulo de elasticidade estático; $\mathrm{E}_{0}=$ módulo em transição vítrea; $\delta=$ constante; $\mathrm{k}$ e $\mathrm{h}=$ expoentes, $0<\mathrm{k}<\mathrm{h}<1 ; \beta=$ constante; $\tau_{\mathrm{E}}=$ tempo característico, cujo valor varia apenas com a temperatura; $\mathrm{C} 1$ e $\mathrm{C} 2=$ constantes do modelo WLF para translação e moldagem da curva mestra

As curvas mestras têm sido utilizadas por diversos pesquisadores para descrever e representar as características viscoelásticas de ligantes e misturas asfálticas em uma ampla faixa de temperatura e frequência [11, 14, 16, 39, 40, 48]. A Figura 6 traz a comparação de todas as curvas mestras das misturas estudadas. É possível verificar que o módulo dinâmico cresce em função da frequência. Este crescimento se deve ao fato de que, quando a frequência é aumentada, existe um menor tempo em carga, ou seja, não há tempo para manifestações de deformações viscoelásticas. Além disso, quando a frequência é muito alta, os valores de módulo atingem seu maior pico, ou seja, praticamente, só existem deformações elásticas no material, sem relaxação. Ainda, em baixas frequências, o tempo de carregamento é maior, assim, as deformações viscoelásticas podem se manifestar em sua totalidade, o que provoca um módulo dinâmico menor. O menor valor verificado para o módulo dinâmico é encontrado nas frequências mais baixas, o que explica o formato da curva mestra.

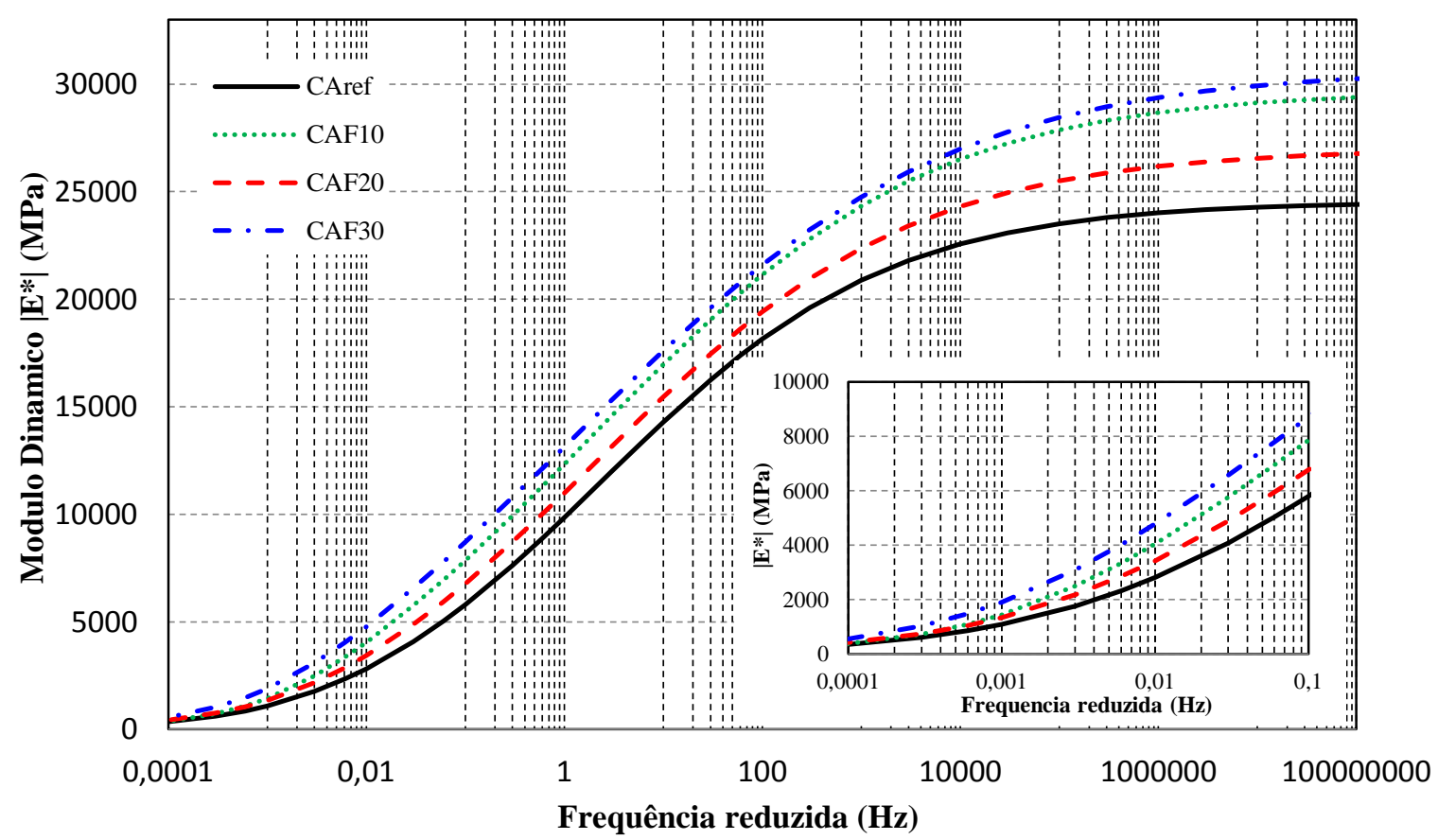

Figura 6: Comparação curva mestra para todas as misturas à temperatura de $20^{\circ} \mathrm{C}$ 
Através da curva mestra das misturas foi possível verificar o aumento da rigidez com a inserção de fresado, visto que o $E^{*}$ aumenta em função da frequência. Através destes dados nota-se que a mistura que apresentou maior rigidez foi a CAF30, seguida pela CAF10, CAF20 e, por último, a CAref, mesmo padrão apresentado para os ensaios de módulo de resiliência. Esse resultado também foi considerado inesperado, visto que, geralmente, a adição de fresado nas misturas aumenta a rigidez, o que, neste caso, não se confirmou em sua totalidade, sendo que a mistura com adição de $10 \%$ de fresado apresentou-se mais rígida que a mistura com adição de $20 \%$.

Tal fator pode ser explicado devido à heterogeneidade do material reciclado ou, ainda, pelas características do ligante envelhecido presente neste material, onde o ligante asfáltico exerce forte efeito na rigidez das misturas. Além disso, outro fator que poderia explicar essa inversão nos dados seria quanto à disposição dos materiais nas amostras, visto que estas foram moldadas em laboratório, com auxílio de misturador e compactador giratório. Ainda assim, o experimento indica que a adição de fresado em misturas asfálticas afeta o módulo e aumenta a rigidez, visto que a mistura menos rígida foi a que não apresentava material reciclado em sua composição.

A Figura 7 apresenta a curva mestra do ângulo de fase para todas as misturas. Através desses dados, é possível verificar que a mistura CAF10 apresenta os maiores ângulos de fase à frequência mais baixa de $0,0001 \mathrm{~Hz}$, havendo inversão de comportamento, à medida em que aumentam as frequências, a partir de 0,01 $\mathrm{Hz}$, retornando à rigidez esperada. Além disso, na região da esquerda, com frequências mais baixas ou temperaturas mais elevadas, o ligante não tem capacidade elástica, onde, ainda, o pico de comportamento da mistura recebe forte influência do esqueleto mineral. Esta afirmação reforça a hipótese de que a CAF10 talvez apresente alguma disposição diferenciada dos materiais dentro das amostras, visto que é a mistura que apresenta maior pico no gráfico. Assim, reforça-se que, no domínio das altas frequências, que representam mais a parcela elástica, a inclusão de fresado, por conter já o ligante oxidado, eleva os valores de rigidez.

Esse aumento de rigidez, em frequências elevadas, correspondendo a temperaturas muito baixas, pode induzir concentração de tensões e gerar trincamentos, quando isto não é considerado no projeto estrutural [40]. Isto não representa um problema no Brasil, visto que não se tem problemas relacionados a temperaturas negativas.

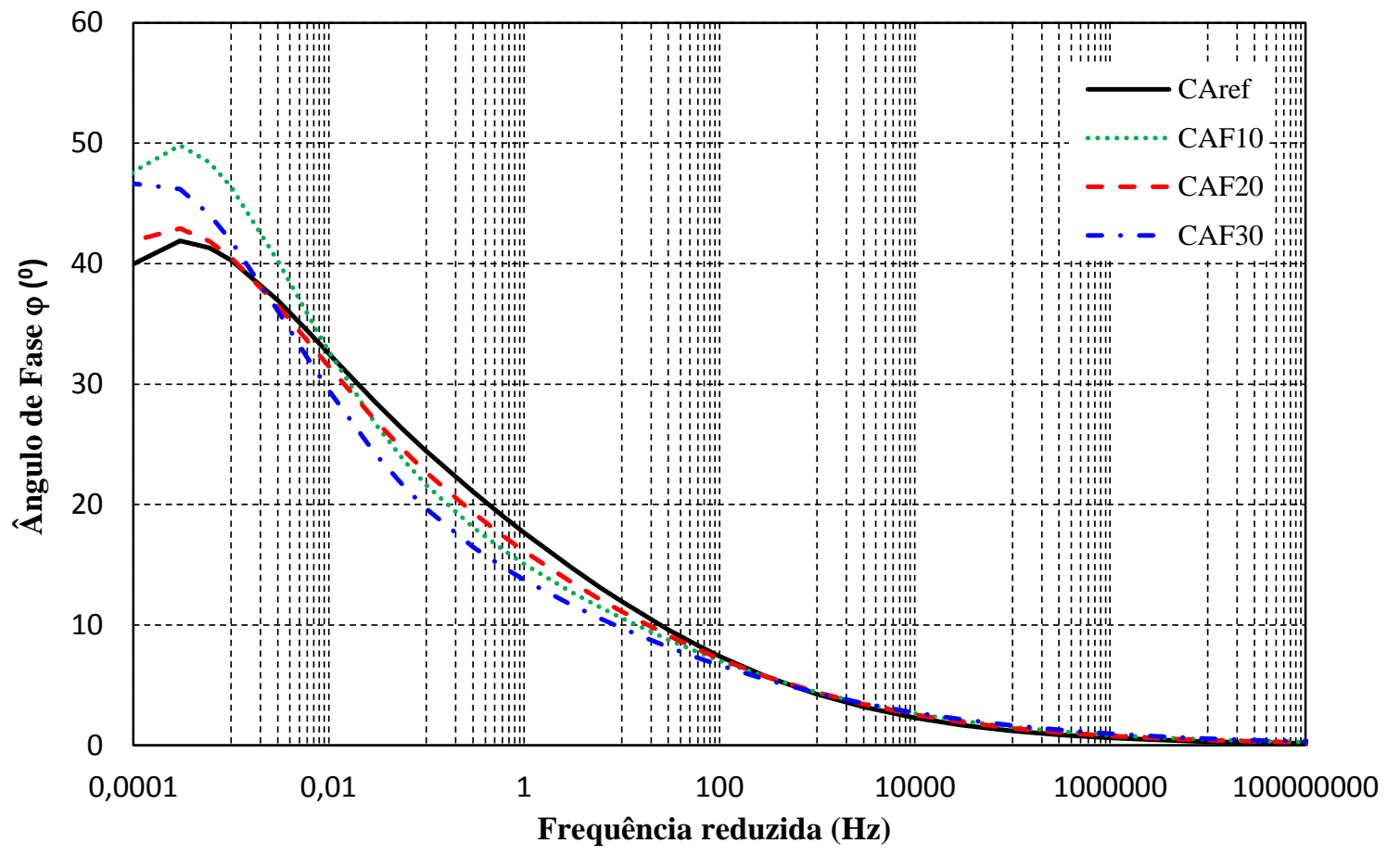

Figura 7: Comparação curva mestra do ângulo de fase para todas as misturas

\subsection{Resistência Mecânica}

A Tabela 5 apresenta as médias dos resultados de $\mathrm{RT}$ à $25^{\circ} \mathrm{C}$, é possível verificar que os valores de resistência aumentam conforme se eleva o teor de fresado na mistura, o que também é possível verificar através da Figura 8. Além disso, observa-se que os resultados estão de acordo com o limite imposto pelo DNIT 031/2006 [33] para CA, o qual recomenda que o valor mínimo seja de 0,65 MPa. Os resultados são 
bastante positivos, todavia uma análise acerca do comportamento à fadiga será necessária em pesquisas futuras.

Tabela 5: Resultados de MR e RT à temperatura de $25^{\circ} \mathrm{C}$

\begin{tabular}{ccc}
\hline Mistura & $R T(\mathrm{MPa})$ & $D P(\mathrm{MPa})$ \\
\hline CAref & 1,42 & 0,14 \\
CAF10 & 1,79 & 0,23 \\
CAF20 & 2,08 & 0,23 \\
CAF30 & 2,36 & 0,12 \\
\hline
\end{tabular}

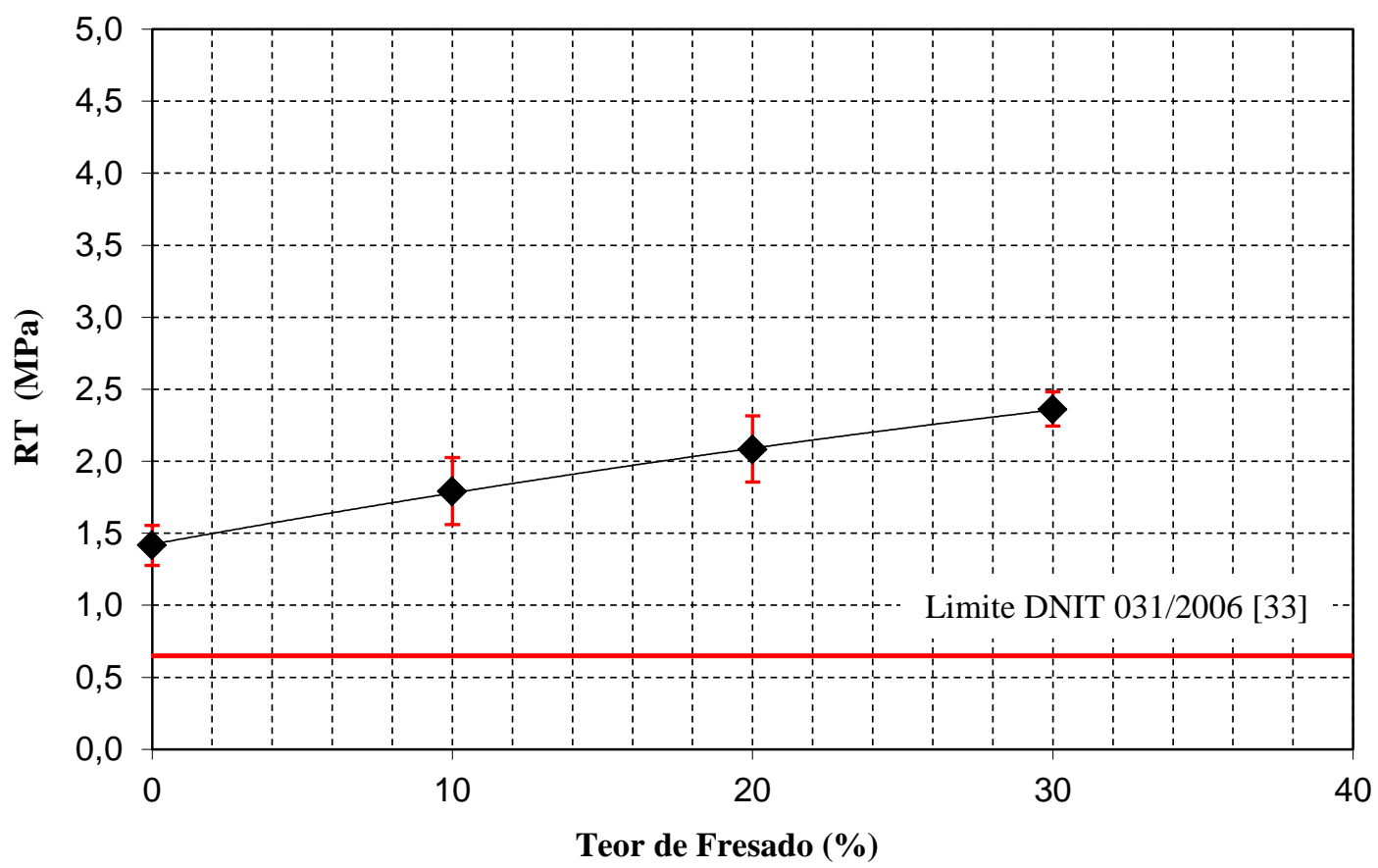

Figura 8: Resultados de RT a $25^{\circ} \mathrm{C}$ em função do teor de fresado

O ensaio de FN avaliou a resistência frente à deformação permanente das misturas. Na Tabela 6 estão os resultados médios com seus respectivos desvios-padrões e coeficientes de variação (CV). É possível certificar que os resultados de CV atenderam à norma AASHTO T 79 [42]. De acordo com os parâmetros da norma, o CV para duas amostras ensaiadas não deve exceder o valor de $14,1 \%$ ao atingir o FN, logo, através da análise da Tabela 6 , nota-se que os coeficientes de variação de todas as misturas se apresentaram abaixo deste valor, atendendo, assim, o limite imposto pela norma.

Tabela 6: Resultado do FN para as amostras e média de cada mistura

\begin{tabular}{|c|c|c|c|c|}
\hline Mistura & $F N($ ciclos $)$ & Média & $D P($ ciclos $)$ & $C V(\%)$ \\
\hline \multirow{2}{*}{ CAref } & 60 & \multirow{2}{*}{60} & \multirow{2}{*}{0,78} & \multirow{2}{*}{1,19} \\
\hline & 59 & & & \\
\hline \multirow{2}{*}{ CAF10 } & 140 & \multirow{2}{*}{150} & \multirow{2}{*}{14,14} & \multirow{2}{*}{9,43} \\
\hline & 160 & & & \\
\hline \multirow{2}{*}{ CAF20 } & 250 & \multirow{2}{*}{262} & \multirow{2}{*}{17,68} & \multirow{2}{*}{6,73} \\
\hline & 275 & & & \\
\hline \multirow{2}{*}{ CAF30 } & 530 & \multirow{2}{*}{540} & \multirow{2}{*}{14,14} & \multirow{2}{*}{2,62} \\
\hline & 550 & & & \\
\hline
\end{tabular}

Fica clara a influência do teor de ligante das misturas na sua resistência à tração e, ainda, que a quantidade de ligante envelhecido afeta diretamente esse parâmetro. O FN aumenta conforme o teor de fresado nas misturas também aumenta (Figura 9), onde, consequentemente, o teor de ligante adicionado é 
menor. Isto é evidenciado pela quantidade de ligante antigo presente, ou seja, à medida em que o teor de ligante antigo é maior, a resistência à deformação permanente da mistura também é maior, visto que o ligante envelhecido apresenta maior rigidez que o ligante novo, o que reflete diretamente no FN. Assim, de acordo com este ensaio, é possível afirmar que o material reciclado aumenta a resistência, ao passo que a deformação permanente não é um problema quando da inserção de fresado na composição das misturas.

Para tráfego médio, o valor de FN deve ser maior do que 300 ciclos, sendo que, para tráfego pesado, esse valor aumenta para 750 ciclos [49]. Logo, seguindo esse parâmetro, apenas a mistura CAF30 apresenta resultado positivo quanto à análise do número de ciclos para tráfego médio, sendo que nenhuma delas atende ao critério de tráfego pesado.

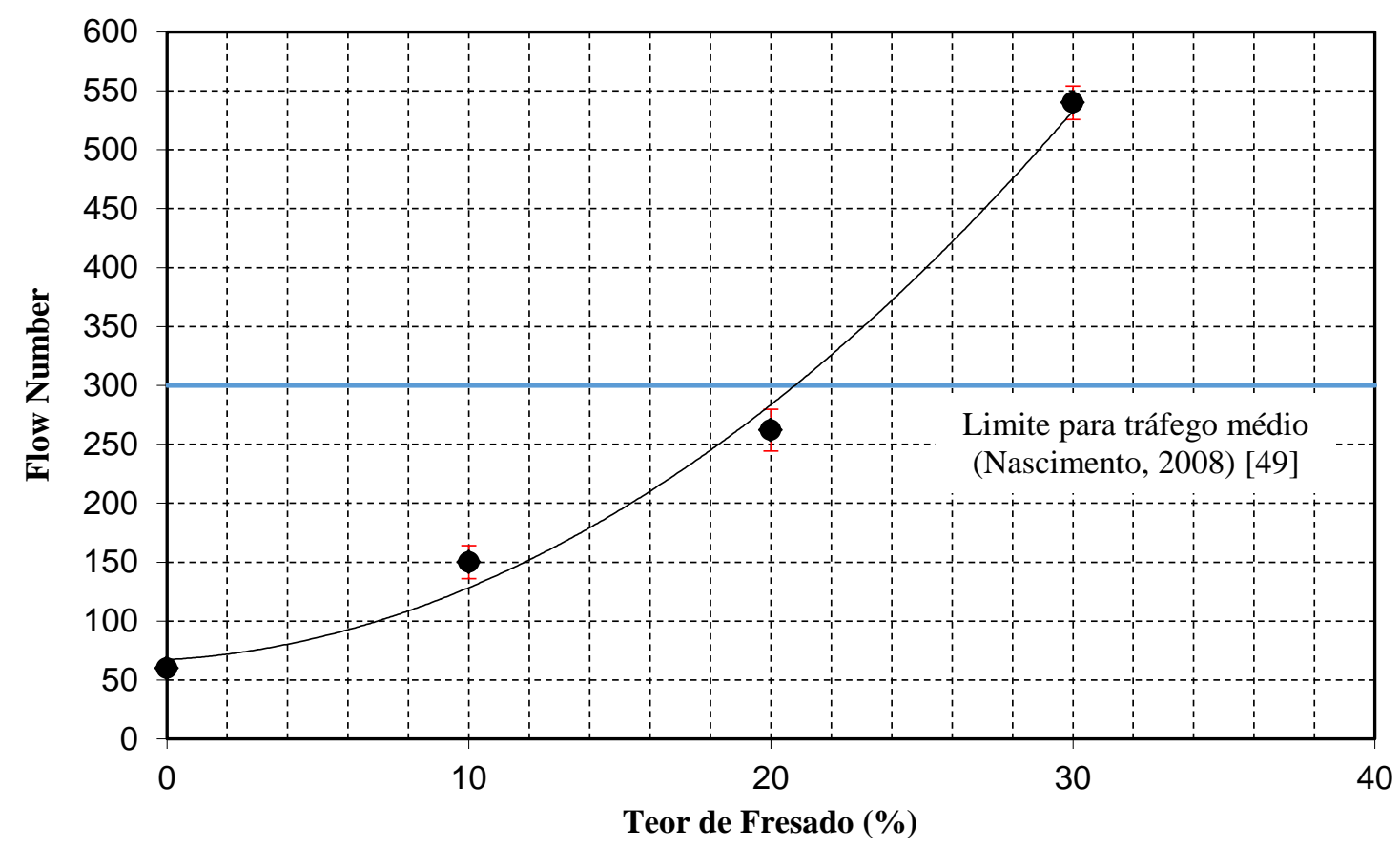

Figura 9: Resultado do FN à temperatura de $60^{\circ} \mathrm{C}$ em função do teor de fresado das misturas

\subsection{Adesão/Coesão}

O ensaio de Lottman Modificado avaliou a propriedade de adesividade das misturas asfálticas considerando o efeito deletério da água. A Tabela 7 apresenta as médias dos resultados dos ensaios de resistência à tração por compressão diametral das amostras com e sem condicionamento (RT' e RT, respectivamente) bem como a RRT (Resistência Retida à Tração).

Tabela 7: Resultados dos ensaios de efeito deletério da água e do ensaio de perda de massa

\begin{tabular}{c|ccc|cc}
\hline \multirow{2}{*}{ Mistura } & \multicolumn{3}{|c|}{$\begin{array}{c}\text { Ensaio de RRT AASHTO T } 283 \text { e NBR } \\
15617 / 2011\end{array}$} & \multicolumn{2}{c}{$\begin{array}{c}\text { Ensaio de perda de massa } \\
\text { NBR 15140/2004 }\end{array}$} \\
\cline { 2 - 6 } & $R T^{\prime}(\mathrm{MPa})$ & $R T(\mathrm{MPa})$ & $R R T(\%)$ & Média $(\%)$ & DP $(\%)$ \\
\hline CAref & 1,13 & 1,03 & 110 & 5,29 & 0,58 \\
CAF10 & 1,50 & 1,45 & 103 & 6,35 & 0,29 \\
CAF20 & 1,31 & 1,67 & 79 & 6,68 & 0,64 \\
CAF30 & 1,21 & 1,79 & 68 & 8,11 & 0,96 \\
\hline
\end{tabular}

Pelos dados das Tabela 7 é possível afirmar que, tanto a mistura CAref, apenas com agregados convencionais, como as demais misturas, contendo agregados reciclados da pavimentação, apresentaram resultados satisfatórios quanto ao efeito deletério da ação da água, sendo esse efeito tendo queda de valor conforme a adição de material fresado em sua composição.

A Figura 10 apresenta os resultados dos ensaios de RT das amostras com e sem condicionamento. Notase que, para as amostras sem condicionamento, conforme aumenta o teor de fresado na mistura, maiores são os valores de resistência. Já para as amostras com condicionamento, as amostras da mistura de referência 
CAref apresentaram valores diferenciados das demais, estas, apresentaram valores decrescentes conforme aumento do teor de fresado na mistura.

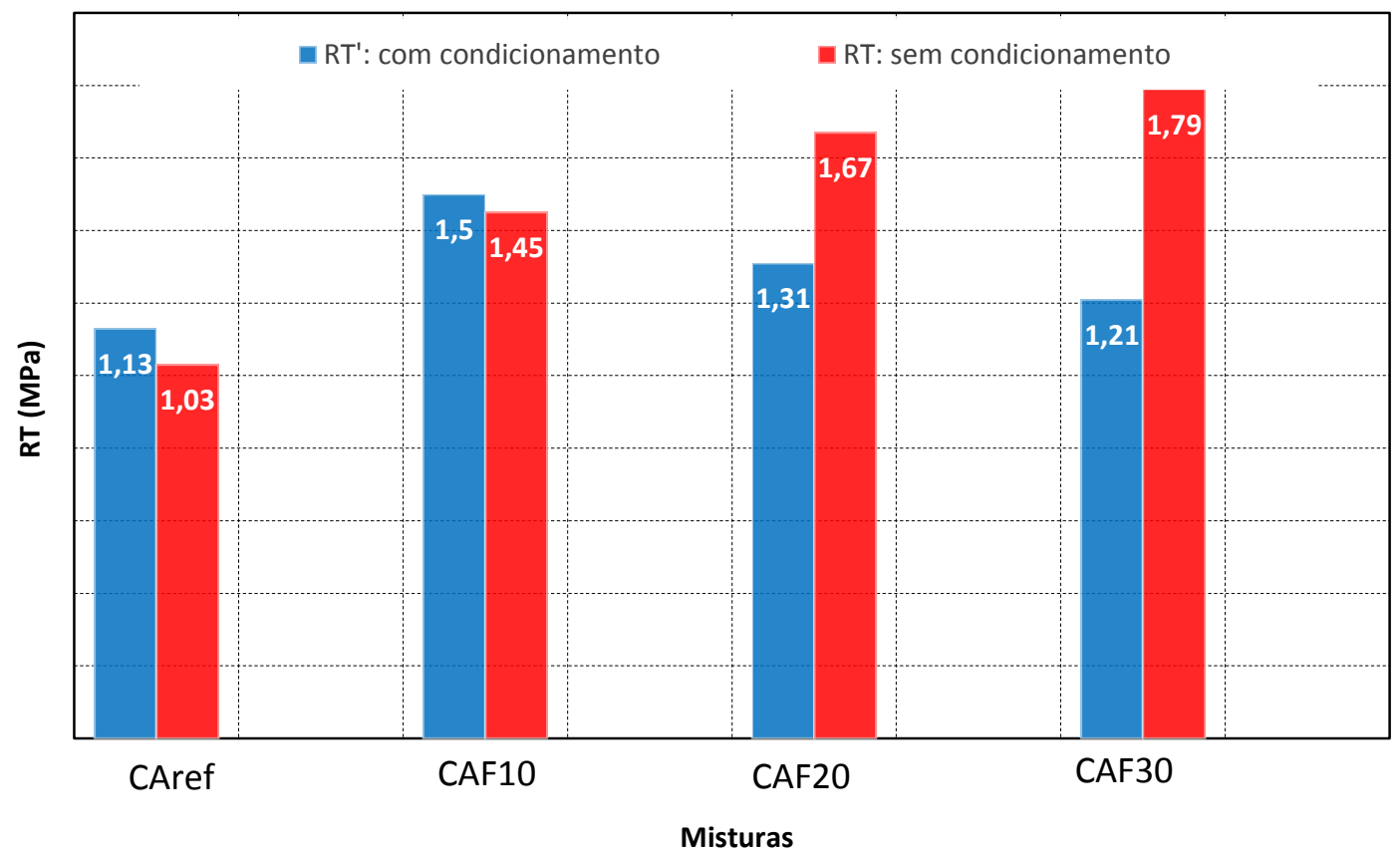

Figura 10: Resultados dos ensaios de resistência à tração do Lottman Modificado

De acordo com a metodologia Superpave [44], os valores de referência preconizados para RRT são aqueles acima de $80 \%$. Através dos resultados da Figura 11, é possível verificar que apenas a mistura com o maior teor de fresado (CAF30) não respeitou o limite da metodologia. Apesar de a mistura CAF20 ter ficado $1 \%$ abaixo do recomendado pela metodologia Superpave. A maioria dos departamentos estaduais de transportes norte-americanos utilizam o limite de 70\% [50]. Logo, apenas a mistura CAF30 não atende o limite recomendado, estando abaixo dos $70 \%$. Além disso, é possível verificar que, à medida em que se aumenta o teor de ligante antigo, a RRT diminui, ao passo que, conforme a quantidade de ligante novo é adicionada, a RRT aumenta. Ou seja, a inserção de ligante envelhecido não é favorável à resistência retida à tração, mesmo assim, isto não representa um problema, visto que pode ser facilmente resolvido com adição de cal, por exemplo [51]. 


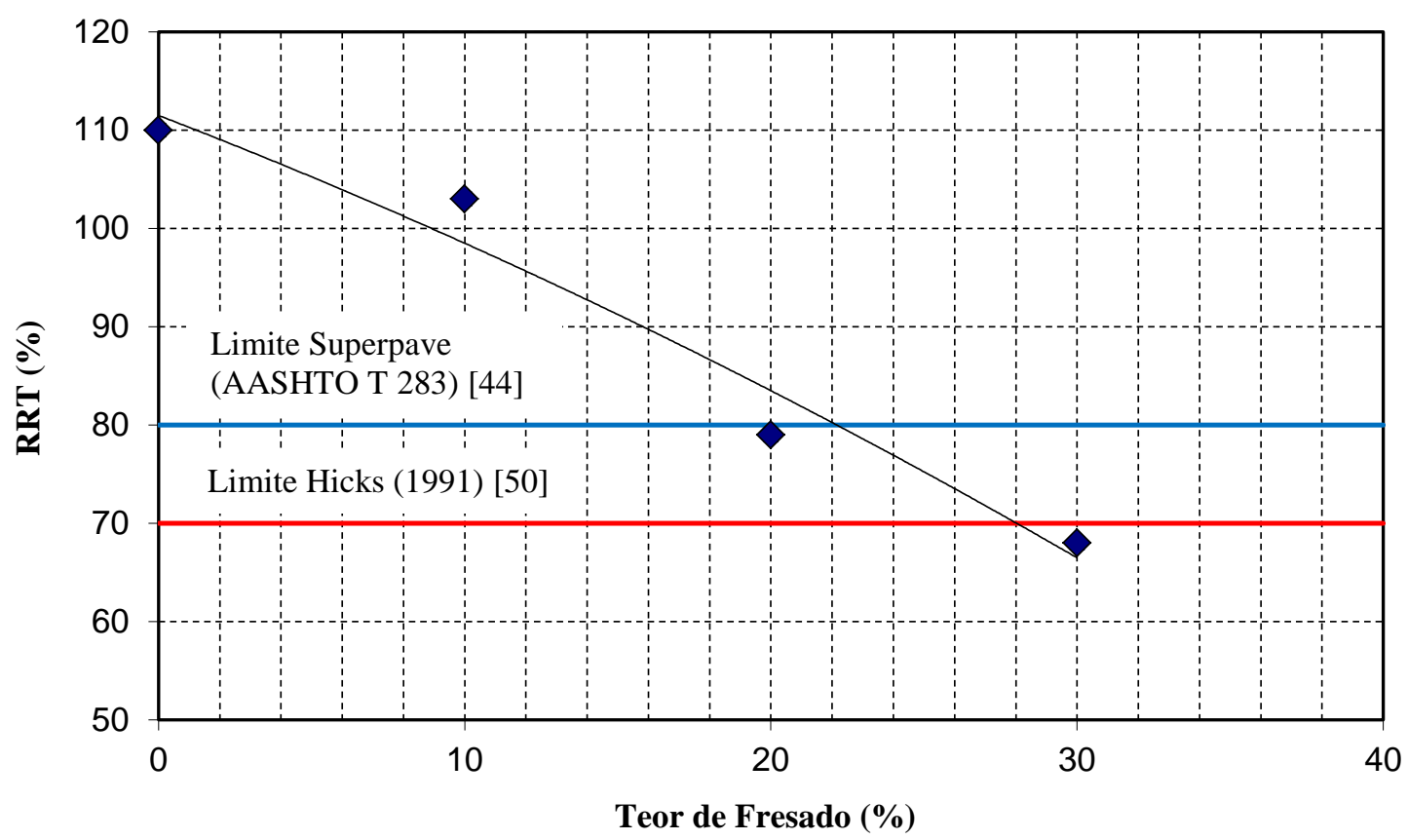

Figura 11: Resultado do ensaio de efeito deletério da água em função do teor de fresado.

Para o ensaio de resistência ao desgaste por perda de massa Cântabro, a Tabela 7 mostra os resultados obtidos e, através dos dados apresentados, pode ser observado que, conforme aumenta o teor de fresado nas misturas, os valores de perda de massa, em média, também crescem, o que significa que o fresado aumenta a tendência ao desgaste.

A Figura 12 mostra os mesmos resultados versus teor de fresado. Nota-se que, para as misturas contendo material fresado, o desvio padrão aumenta à medida que aumenta a perda de massa das amostras. Ainda, é possível verificar que o desgaste é maior à medida que o teor de ligante antigo é maior, e que o inverso ocorre para o teor de ligante novo adicionado. Além disso, o desgaste por abrasão final, realizado através das médias dos ensaios para cada mistura, apresenta valores individuais bastante inferiores dos $20 \%$ exigido pela norma para misturas porosas ABNT NBR 15140/2004 [46].

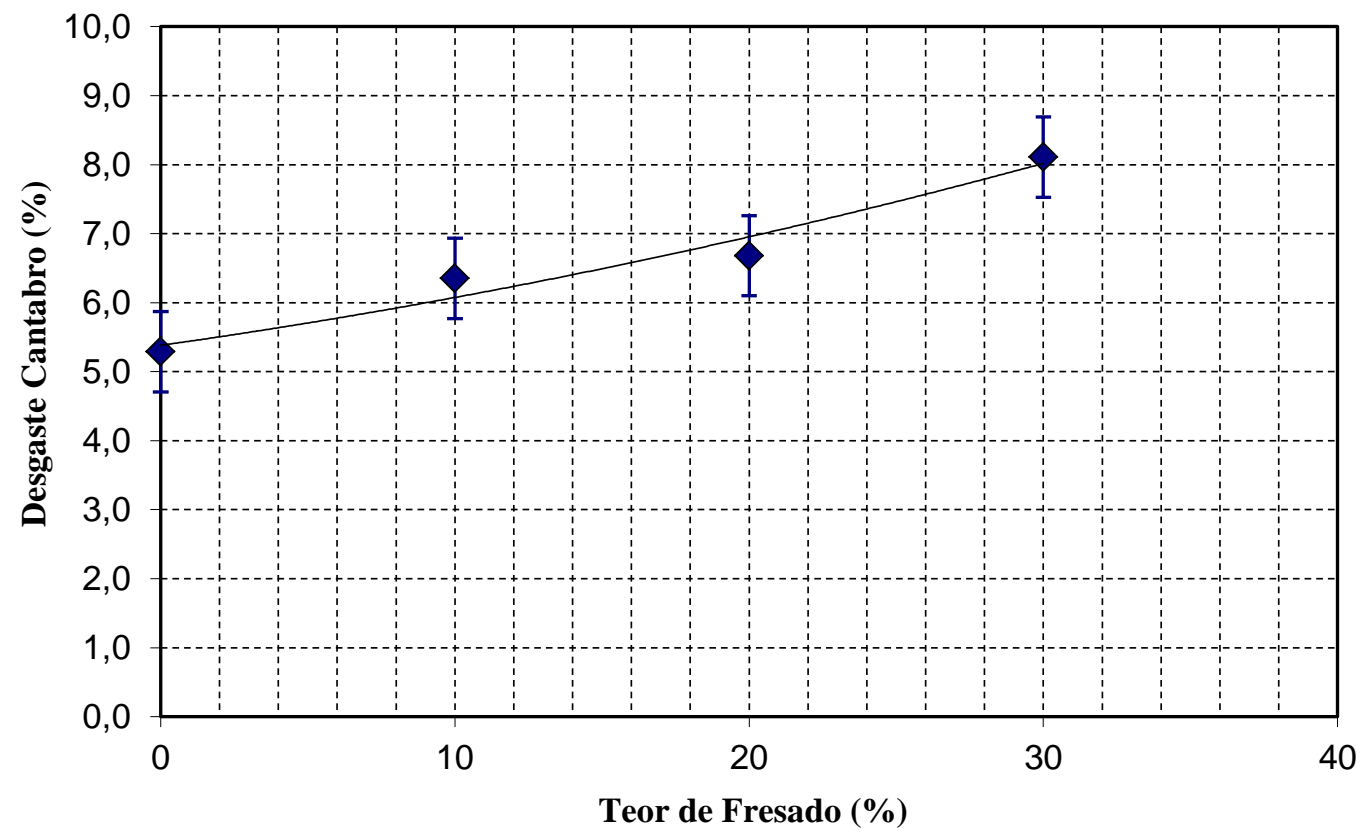

Figura 12: Resultado do ensaio de perda de massa em função do teor de fresado 


\section{CONCLUSÕES}

Este trabalho teve como objetivo analisar, através de ensaios laboratoriais, o comportamento do material fresado (RAP) em substituição ao agregado natural, para aplicação em obras de construção e restauração de pavimentos flexíveis. Assim, através da reutilização do material asfáltico oriundo da fresagem e, aplicando as técnicas de reciclagem a quente, para os ensaios laboratoriais, foram avaliadas em quesitos de rigidez, resistência mecânica e nas propriedades de adesão/coesão, obedecendo as normas vigentes, as quais este material poderá vir a ser aplicado.

Através dos resultados de dosagem é possível afirmar que a utilização de fresado em misturas asfálticas gera uma economia de até $35 \%$ no teor de ligante adicionado, para misturas com adição de $30 \%$ de agregado reciclado.

A rigidez e a parcela elástica (E1) das misturas aumentam em $6000 \mathrm{MPa}$ com a inserção de $30 \%$ de fresado quando comparada à mistura convencional, o que representa cerca de $20 \%$ de aumento, visto que no ensaio de módulo dinâmico é possível verificar, claramente, que as parcelas elásticas aumentam conforme aumenta o teor de fresado.

No geral, na análise dos resultados de MR e RT, estes apresentaram valores superiores, da ordem de $30 \%$ e $40 \%$, respectivamente, para as misturas contendo $30 \%$ de agregado reciclado, quando comparados com os valores obtidos nos mesmos ensaios para a mistura de referência. Acredita-se que estes resultados tenham sido motivados pela presença do material fresado, que, por sua vez, age elevando a resistência das misturas as quais contém esse material na composição. Em um projeto de pavimento, a análise da rigidez com a resistência à fadiga torna-se relevante.

Com relação à deformação permanente, através do FN, é possível verificar que o fresado aumenta a resistência em quase $90 \%$, com a adição de $30 \%$ deste material, comparada à mistura de referência, funcionando com uma estratégia, principalmente em projetos com grandes espessuras.

A adição de fresado aumenta a perda de massa e reduz a resistência ao efeito deletério da água, não chegando a nenhum limite que possa condenar as misturas, podendo ser utilizada, em algum caso específico, como camada intermediária ou ainda se incorporando cal ou alguma aditivo. Esta propriedade merece atenção no processo de dosagem.

Portanto, é possível afirmar que o material fresado tem alto potencial de redução de consumo de asfalto, além de ser excelente na distribuição de tensões, visto que é um material mais rígido, contribuindo para o projeto estrutural do pavimento.

Assim, ao realizar uma análise geral dos resultados, é possível concluir que a adição de material fresado em misturas asfálticas tem comprovada viabilidade técnica, visto que os experimentos de laboratório indicaram melhora no comportamento destas misturas quando comparadas a misturas convencionais. Na perspectiva de continuidade os estudos envolvendo fadiga e análise microestrutural, bem como maiores teores de RAP tornam-se relevantes.

\section{AGRADECIMENTOS}

Os autores agradecem à FAPERGS, Capes e CNPQ pelas bolsas e à ANP/PETROBRAS pelo suporte financeiro que possibilitou a infraestrutura laboratorial, no âmbito da Rede Temática do Asfalto.

\section{BIBLIOGRAFIA}

[1] YODER, E. J., WITCZAK, M. W, Principles of Pavement Design, 2 ed., New York, John Wiley \& Sons Inc., 1975.

[2] PAPAgiannakiS, A. T., MASSAD, E. A., Pavement Design and Materials, John Wiley \& Sons, Hoboken, p. 542, 2008.

[3] BeRnUCCI, L., MOTTA, L. G., CERATTI, J. A. P., et al., Pavimentação Asfáltica: Formação Básica para Engenheiros, 1 ed., Rio de Janeiro, ABEDA, 2008.

[4] FONSECA, P., GUIMARÃES, C., GOMES, V., et al., Estudo de Material Fresado para Incorporação em Misturas Betuminosas a Quente com Altas Taxas de Reciclagem. Universidade do Minho, C-TAC Centro do Território Ambiente e Construção, Campus de Azurém, Guimarães, Portugal, 2013.

[5] BRESSI, S., CAVALLI, M. C., PARTL, M. N., et al., "Particle clustering phenomena in hot asphalt mixtures with high contente of reclaimed asphalt pavements", Journal Construction and Building Materials, v. 100,2015 . DOI: 10.1016 . 
[6] MOHAJERI, M., MOLENAAR, A. A. A., VAN DE VEM, M. F. C., "Bleding Simulation of RA and Virgin Binders in Hot Recycled Mixtures", In: $8^{\text {th }}$ RILEM International Symposium on Testing and Characterization of Sustainable and Innovative Bituminous Materials. v. 11, 2015.

[7] ROWE, G. M., BARRY, J., CRAWFORD, K. "Evaluation of a 100\% Rap Recycling Project in Fort Wayne, Indiana", In: $8^{\text {th }}$ RILEM International Symposium on Testing and Characterization of Sustainable and Innovative Bituminous Materials. v. 11, 2015.

[8] ZUBARAN, M., MOTTA, L. M. G., “Avaliação de misturas asfálticas recicladas mornas em laboratório e usina de asfalto", In: $42^{a} R A P V$ : Reunião Anual de Pavimentação, Foz do Iguaçu, PR, 2015. Anais.

[9] PIRES, G. M., SPECHT, L. P., PINHEIRO, R. J. B., et al., "Comportamento mecânico de material fresado após processo de estabilização granulométrica e química por meio da incorporação de cimento e cinza de casa de arroz moída”, Revista Matéria, v. 21, n. 2. Rio de Janeiro, 2016.

[10] RENAUD, C. L. R. S. A., Module de rigidité et comportement em fatigue des enrobés bituminuex. Expérimentations et nouvelles perspectives d'analyse. These pour l'obtention du grade de docteur, Ecole Centrale Paris, novembre, 1996.

[11] DI BENEDETTO, H., OLARD, F., SAUZÉAT, C., et al., Linear Viscoelastic Behaviour of Bituminous Materials: from binders to mixes. Road Materials and Pavements Design. Departement Génie Civil et Bátiment, Ecole Nationale des TPE (ENTPE), 41p, 2004.

[12] DANIEL, J. S., LACHANCE, A., "Mechanistic and volumetric properties of asphalt mixtures with RAP”, Journal of the Transportation Research Board, v. 1929, 2005.

[13] KIM, Y. R., Modeling of Asphalt Concrete, McGraw-Hill Construction. American Society of Civil Engineers, 2009.

[14] COUTINHO, R. P., FREIRE, R. A., CASTElO BRANCO, V. T. F., et al., Identificação do comportamento viscoelástico não-linear e do dano em misturas asfálticas utilizando testes de varredura de tensão. Revista Transportes, v. 19, n. 3, pp. 35-41, 2011.

[15] SILVA, S. A. T., VIDAL, P. J. F., HOLANDA, A. S., et al., "Análise viscoelástica de pavimentos asfálticos utilizando elementos finitos e infinitos", Revista Transportes, v. 21, n. 3. P. 5-13, 2013.

[16] BASUENY, A., CARTER, A., PERRATON, D., et al., "Laboratory Evaluation of Complex Modulus and Fatigue Resistance of Asphalt Mixtures with RAP”, In: $8^{\text {th }}$ RILEM International Symposium on Testing and Characterization of Sustainable and Innovative Bituminous Materials. v. 11, 2015.

[17] MOREIRA, J. P. V., PEREIRA, P., CORREIA, A. G., "Reutilização de material fresado em camadas estruturais de pavimento", In: IV Congresso Rodoviário Português - Centro de Congressos do Estoril, 2003.

[18] MENCHING, D. J., DANIEL, J. S., BENNERT, T., et al., "Low temperature properties of plant produced RAP mixtures in the Northeast”, Journal of Road Materials and Pavement Design, v. 15, 2014.

[19] SEGUNDO, I. G. R., CASTELO BRANCO, V. T. F., VASCONCELLOS, K. L., et al., "Misturas asfálticas recicladas a quente com incorporação de elevado percentual de fresado como alternativa para camada de módulo elevado", Revista Transportes, v. 24, n 4. P. 85-94, 2016.

[20] VASCONCELOS, K. L., SOARES, J. B., "Influência do percentual de fresado e do envelhecimento de curto prazo na dosagem de misturas asfálticas recicladas a quente", In: XVIII ANPET - Congresso de Pesquisa e Ensino em Transportes. Anais. Florianopolis/SC, 2004.

[21] DANIEL, J.S., POCHILY, J., BOISVERT, D., Can More Reclaimed Asphalt Pavement Be Added? Study of Extracted Binder Properties from Plant Produced Mixtures with up to $25 \%$ Reclaimed Asphalt Pavement. Transportation Research Record: Journal of the Transportation Research Board, v. 2180, Transportation Research Board of the National Academies, Washington, D.C., pp. 19-29, 2010.

[22] MOGAWER, W., BENNERT, T., DANIEL, J.S., et al., "Performance Characteristics of Plant Produced High RAP Mixtures", Journal of Road Materials and Pavement Design, v. 13, Supplement 1, 2012.

[23] DEPARTAMENTO NACIONAL DE ESTRADAS DE RODAGEM, DNER-ME 053/94: Misturas betuminosas - percentagem de betume, Rio de Janeiro, 1994.

[24] ASSOCIAÇÃO BRASILEIRA DE NORMAS TÉCNICAS, NBR 15619: Misturas asfálticas Determinação da massa específica máxima medida em amostras não compactadas, Rio de Janeiro, 2012.

[25] DEPARTAMENTO NACIONAL DE ESTRADAS DE RODAGEM, DNER-ME 035/98: Agregados Determinação da abrasão Los Angeles - Método de Ensaio, Rio de Janeiro, 1998. 
[26] DEPARTAMENTO NACIONAL DE ESTRADAS DE RODAGEM, DNER-ME 089/94: Agregados Avaliação da durabilidade pelo emprego de soluções de sulfato de sódio ou de magnésio - Método de Ensaio, Rio de Janeiro, 1994.

[27] DEPARTAMENTO NACIONAL DE ESTRADAS DE RODAGEM, DNER-ME 054/97: Agregados Equivalente de areia - Método de Ensaio, Rio de Janeiro, 1997.

[28] AMERICAN ASSOCIATION OF STATE HIGHWAY AND TRANSPORTATION OFFICIALS, AASHTO T 316 (2013) Standard Method of Test for Viscosity Determination of Asphalt Binder Using Rotational Viscometer, D. C.

[29] AMERICAN ASSOCIATION OF STATE HIGHWAY AND TRANSPORTATION OFFICIALS, AASHTO T 315: Standard Method of Test for Determining the Rheological Properties of Asphalt Binder Using a Dynamic Shear Rheometer (DSR), D. C., 2012

[30] AMERICAN ASSOCIATION OF STATE HIGHWAY AND TRANSPORTATION OFFICIALS, AASHTO T 240: Standard Method of Test for Effect of Heat and Air on a Moving Film of Asphalt (Rolling Thin-Film Oven Test), D. C., 2013

[31] AMERICAN ASSOCIATION OF STATE HIGHWAY AND TRANSPORTATION OFFICIALS, AASHTO M 332: Standard Specification for Performance-Grade Asphalt Binder Using Multiple Stress Creep Recovery (MSCR) Test. Washington, D. C., 2014

[32] AMERICAN ASSOCIATION OF STATE HIGHWAY AND TRANSPORTATION OFFICIALS, AASHTO T 313: Standard Method of Test for Determining the Flexural Stiffness of Asphalt Binder Using the Bending Beam Rheometer (BBR), D. C., 2012

[33] DEPARTAMENTO NACIONAL DE INFRAESTRUTURA DE TRANSPORTES, DNIT-ES 031/2006: Pavimentos flexíveis - Concreto asfáltico - Especificação de serviço, Rio de Janeiro, 2006.

[34] MENDES, L. O., MARQUES, G. L. O., "Avaliação da influência do Método Bailey no processo de dosagem e desempenho de misturas asfálticas", Revista Transportes, v. 20, n. 4. p. 35-43, 2012.

[35] AMERICAN ASSOCIATION OF STATE HIGHWAY AND TRANSPORTATION OFFICIALS, AASHTO M 323-12: Standard Specification for Superpave Volumetric Mix Design, Washington, D.C., 2013.

[36] DEPARTAMENTO NACIONAL DE INFRAESTRUTURA DE TRANSPORTES, DNIT-ME 135/2010: Pavimentação asfáltica - Misturas asfálticas - Determinação do módulo de resiliência - Método de ensaio, Rio de Janeiro, 2010.

[37] AMERICAN ASSOCIATION OF STATE HIGHWAY AND TRANSPORTATION OFFICIALS, AASHTO T 342: Determining Dynamic Modulus of Hot-mix Asphalt Concrete Mixtures, Washington, D.C., 2005.

[38] DI BENEDETTO, H., CORTÉ, J. F., Matériaux routiers, 2, Hermes-Lavoisier, Paris, 2005.

[39] OTTO, G. G., Misturas Asfálticas Mornas - Verificação da Fadiga e do Módulo Complexo, Dissertação M.Sc., Universidade Federal de Santa Catarina, Florianópolis, 2009.

[40] SPECHT, L. P., BABADOPULOS, L. F. A. L., DI BENEDETTO, H., et al., "Application of the theory of viscoelasticity to evaluate the resilient modulus test in asphalt mixes", Construction and Building Materials, v. 149, pp.648-658, 2017.

[41] DEPARTAMENTO NACIONAL DE INFRAESTRUTURA DE TRANSPORTES, DNIT-ME 136/2010: Pavimentação asfáltica - Misturas asfálticas - Determinação da resistência à tração por compressão diametral - Método de ensaio, Rio de Janeiro, 2010.

[42] AMERICAN ASSOCIATION OF STATE HIGHWAY AND TRANSPORTATION OFFICIALS, AASHTO TP 79-12: Determining the Dynamic Modulus and Flow Number for HMA Using the Asphalt Mixture Performance Tester (AMPT), Washington, D.C., 2005.

[43] ASSOCIAÇÃO BRASILEIRA DE NORMAS TÉCNICAS, NBR 16505: Misturas asfálticas Resistência à deformação permanente utilizando o ensaio uniaxial de carga repetida, Rio de Janeiro, 2016.

[44] AMERICAN ASSOCIATION OF STATE HIGHWAY AND TRANSPORTATION OFFICIALS, AASHTO T 283: Standard Method of Test for Resistance of Compacted Hot Mix Asphalt (HMA) to MoistureInduced Damage, Washington, D.C., 2007.

[45] ASSOCIAÇÃO BRASILEIRA DE NORMAS TÉCNICAS, NBR 15617: Misturas asfálticas Determinação do dano por umidade induzida, Rio de Janeiro, 2011. 
[46] ASSOCIAÇÃO BRASILEIRA DE NORMAS TÉCNICAS, NBR 15140: Misturas asfálticas Determinação do desgaste por abrasão cântabro, Rio de Janeiro, 2002.

[47] WILLIAMS, M. L., LANDEL, R. F., FERRY, J. D., "The temperature dependence relaxationmechanism in amorphous polymers and other glass forming liquids", J. Am. Chem. Soc., v. 77, n. 14, pp. 3701-3707, 1955.

[48] YUSOFF, N. I., CHAILlEUX, E., AIREY, G. D., "A Comparative Study of the Influence on shift Factor Equations on Master Curve Construction", International Journal of Pavement Research and Technology, v. 4, n. 6. Nov., 2011.

[49] NASCIMENTO, L.A., Nova abordagem da dosagem de misturas asfálticas densas com uso do compactador giratório e foco na deformação permanente, Dissertação de M.Sc., Universidade Federal do Rio de Janeiro, 2008.

[50] HICKS, R. G., Moisture damage in asphalt concrete. National Cooperative Highway Research Program. Synthesis of Highway Practice 175, Transportation Research Board, Washington, 1991.

[51] BOEIRA, F. D. Estudo do comportamento de concretos asfálticos com diferentes tipos de agregados e cales, Dissertação de M.Sc, Universidade Federal de Santa Maria, 2014. 